\title{
Transcription-Factor-Dependent Control of Adult Hippocampal Neurogenesis
}

\author{
Ruth Beckervordersandforth ${ }^{1}$, Chun-Li Zhang ${ }^{2}$, and Dieter Chichung Lie ${ }^{1}$ \\ ${ }^{1}$ Institute of Biochemistry, Emil Fischer Center, Friedrich-Alexander Universität Erlangen-Nürnberg, \\ 91054 Erlangen, Germany \\ ${ }^{2}$ Department of Molecular Biology, University of Texas Southwestern Medical Center, Dallas, Texas 75390 \\ Correspondence: chi.lie@fau.de
}

Adult-generated dentate granule neurons have emerged as major contributors to hippocampal plasticity. New neurons are generated from neural stem cells through a complex sequence of proliferation, differentiation, and maturation steps. Development of the new neuron is dependent on the precise temporal activity of transcription factors, which coordinate the expression of stage-specific genetic programs. Here, we review current knowledge in transcription factor-mediated regulation of mammalian neural stem cells and neurogenesis and will discuss potential mechanisms of how transcription factor networks, on one hand, allow for precise execution of the developmental sequence and, on the other hand, allow for adaptation of the rate and timing of adult neurogenesis in response to complex stimuli. Understanding transcription factor-mediated control of neuronal development will provide new insights into the mechanisms underlying neurogenesis-dependent plasticity in health and disease.

$\mathrm{T}_{\mathrm{p}}^{\mathrm{h}}$ he generation of new neurons from stem cells persists in at least two areas of the adult mammalian brain: the subventricular zone (SVZ) of the lateral ventricles and the subgranular zone (SGZ) of the hippocampal dentate gyrus (DG) (Ming and Song 2011). Neurogenesis in the adult DG has particularly gained major attention as there is now convincing evidence for robust adult hippocampal neurogenesis in humans (Eriksson et al. 1998; Spalding et al. 2013) and because there is growing insight into the prominent role of adult neurogenesis in hippocampus-dependent learning and memory and the regulation of mood (Aimone et al. 2011; Sahay et al. 2011; Kheirbek et al. 2012).
Moreover, analysis of aged animals and preclinical models raised the intriguing possibility that disturbance of adult hippocampal neurogenesis contributes to the pathophysiology of cognitive impairment and mood disturbance in aging and neuropsychiatric disorders (Winner et al. 2011).

The generation of new functional DG neurons from neural stem cells is achieved through a complex developmental sequence including proliferation, differentiation, and maturation steps. The developmental progression of a newborn cell is controlled by environment-derived signals and is coordinated by precise changes in the pattern of gene expression (Zhao et al. 2008;

Editors: Fred H. Gage, Gerd Kempermann, and Hongjun Song

Additional Perspectives on Neurogenesis available at www.cshperspectives.org

Copyright (C) 2015 Cold Spring Harbor Laboratory Press; all rights reserved; doi: 10.1101/cshperspect.a018879

Cite this article as Cold Spring Harb Perspect Biol 2015;7:a018879 
R. Beckervordersandforth et al.

Suh et al. 2009; Ming and Song 2011). Consequently, transcription factors as the primary regulators of gene transcription fulfill a central function in coordinating the development of new functional neurons from stem cells. In this review, we first provide an overview of the hippocampal neurogenic lineage. We will then summarize the current knowledge on transcriptional regulators controlling adult hippocampal neurogenesis and will discuss how transcription factors may cooperatively control lineage progression. Finally, we will discuss how transcription factor networks may serve as a convergence point of signaling pathways and provide a platform to wire extrinsic signals into the regulation of development of adult-born DG neurons.

\section{THE HIPPOCAMPAL NEUROGENIC LINEAGE}

The generation of new functional DG neurons from neural stem cells is achieved through a complex developmental sequence that comprises the activation of a quiescent stem cell into a proliferating state, neuronal fate determination of the proliferating precursor cell, neuronal maturation, and functional integration into the hippocampal circuit (Zhao et al. 2008; Suh et al. 2009; Ming and Song 2011). Fate mapping studies combined with expression pattern analyses and the analysis of transgenic reporter mice have led to a model describing distinct developmental stages in adult hippocampal neurogenesis (Fig. 1) (Kempermann et al. 2004).

Specialized astrocytes in the SGZ extending a single glial fibrillary acidic protein (GFAP) or Nestin-positive radial process through the granule cell layer and showing dendrite-like branching in the molecular cell layer, are considered the most undifferentiated precursor in the hippocampal neurogenic lineage (Kempermann et al. 2004). Whether these precursors, which are also referred to as type 1 cells, represent "true" stem cells according to the most stringent criteria is not fully resolved, as there is conflicting data regarding their ability for long-term self-renewal (Bonaguidi et al. 2011; Encinas et al. 2011). It is also of note that a second class of precursor cells with stem-cell characteristics was identified, which divides more quickly than the radial type 1 cells and is morphologically characterized by short, horizontal processes (Lugert et al. 2010). Radial type 1 cells are mostly quiescent or divide very slowly (Lugert et al. 2010; Bonaguidi et al. 2011; Encinas et al. 2011; Beckervordersandforth et al. 2014). Type 1 cells are activated presumably by extrinsic signals, enter cell cycle or accelerate cell-cycle progression, and give rise to consecutive stages of fast dividing precursor cells, namely, type $2 \mathrm{a}$, type $2 \mathrm{~b}$, and type 3 cells. Expansion of the pool of newborn cells is generally considered to occur on the level of the type 2 and to a limited extent at the stage of type 3 precursors (Kronenberg et al. 2003; Kempermann et al. 2004); hence, these precursors are often referred to as transient amplifying progenitor cells. However, it has to be mentioned that emerging data suggests that type 2 a cells may not represent amplifying intermediates in the hippocampal neurogenic lineage (Lugert et al. 2012). Type 2 and type 3 cells display distinct morphology: whereas the former bear short horizontally oriented processes, the latter display longer horizontally oriented and sometimes vertically growing processes. Type $2 \mathrm{a}$ and type $2 \mathrm{~b}$ cells were initially distinguished by the expression of the immature neuron-specific microtubule associated protein doublecortin (DCX) leading to the hypothesis that newborn cells are fate committed to the neuronal lineage on transition from the type $2 \mathrm{a}$ to the type $2 \mathrm{~b}$ precursor stage (Kempermann et al. 2004). Type 3 precursors constitute the last proliferative precursor stage in the adult hippocampal neurogenic lineage. Type 3 cells exit the cell cycle to differentiate into postmitotic immature neurons, characterized by the expression of DCX and the calcium-binding protein calretinin (Brandt et al. 2003).

Maturation of new neurons follows a highly stereotypic sequence and can be roughly divided into two phases. New neurons undergo fast axonal and dendritic growth during the first 2.5 to 3 wk after their birth (Zhao et al. 2006; Sun et al. 2013). They are initially tonically activated by ambient $\gamma$-aminobutyric acid (GABA), followed by activation by GABAergic synaptic inputs (Ge et al. 2006). On the marker level, this phase corresponds approximately with the tem- 


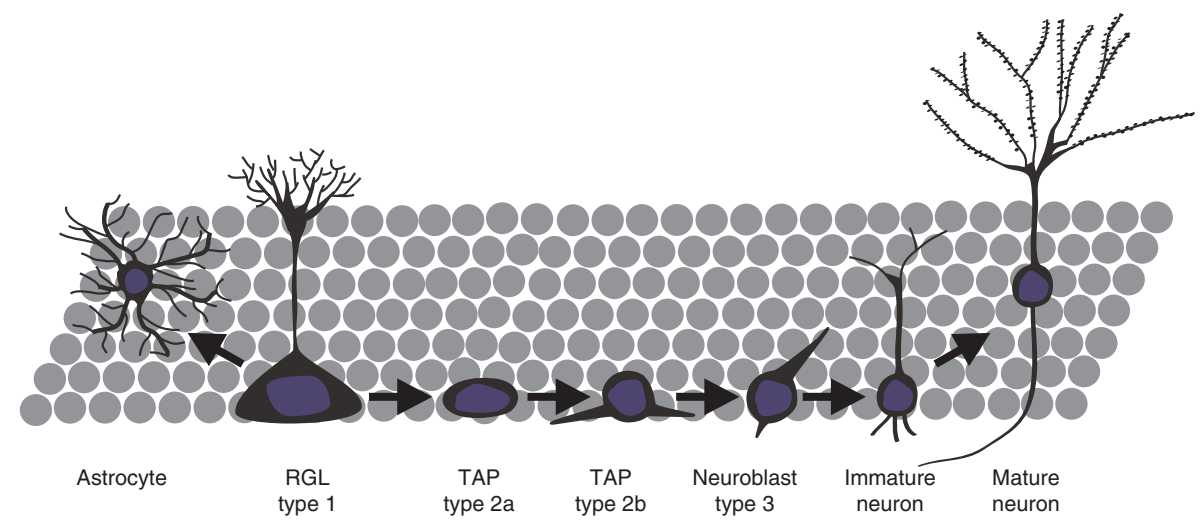

A

\section{GFAP/Sox2}

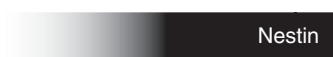

Nestin

Mash1/Ascl1

Tbr2

DCX/calretinin

\begin{tabular}{|c|c|c|c|c|c|}
\hline Sox2 & 'Sox21 & 1 & I & 1 & 'Klf9 \\
\hline$T L X$ & & I & I & I & I \\
\hline Hes5 & & I & I & I & I \\
\hline NFIX & I & I & I & I & I \\
\hline Notch/RBPJK & I & I & I & I & I \\
\hline $\begin{array}{r}\text { FoxO } \\
\text { Bmi }\end{array}$ & I & I & I & I & I \\
\hline Hmga2 & & I & I & I & I \\
\hline REST & |REST & I & I & I & |RES \\
\hline & $\mathbf{I}^{\text {Tis21 }}$ & $\mathbf{I}^{\text {Tis21 }}$ & I & I & $\mathbf{I}^{\mathrm{Tis} 21}$ \\
\hline & $I^{\text {Mash1 }}$ & $I^{\text {Mash1 }}$ & I & I & I \\
\hline & $1^{\text {Tbr2 }}$ & $I^{\text {Tbr2 }}$ & $I_{\text {NeuroD1 }}$ & $I_{\text {Neurno1 }}$ & I \\
\hline & I & I Prox1 & I Prox1 & $I_{\text {Prox1 }}$ & $\mathrm{I}_{\text {Prox }}$ \\
\hline & I & I Sox11 & I Sox11 & I Sox11 & I \\
\hline & I & | Sox4 & I Sox4 & | Sox4 & I \\
\hline & I & I pCREB & I pCREB & I pCREB & I \\
\hline
\end{tabular}

Figure 1. Model of the adult hippocampal neurogenic lineage. (A) Expression of commonly used markers for distinct developmental stages. $(B)$ Expression pattern of transcription factors, for which a function in the adult hippocampal neurogenic lineage has been determined or proposed. Note that the precise expression pattern of nuclear factor $1 \mathrm{X}$-type (NFIX), Bmi, FoxOs, and Hmga2 in the adult hippocampal neurogenic lineage has not been fully established; for these transcription factors, the expression pattern is assumed, based on their proposed function. In the case of the Notch-signal transducer RBPJk, the activity of the Notch/RBPJk pathway is shown. REST, Repressor element 1-silencing transcription; pCREB, phosphorylated CREB; DCX, doublecortin. 
R. Beckervordersandforth et al.

poral window of expression of DCX and calretinin (Ming and Song 2011).

The following maturation phase is initiated around the time of DCX and calretinin downregulation and the appearance of calbindin expression, which is a calcium-binding protein invariably expressed by mature neurons. At about 2.5 wk of age, GABAergic input becomes inhibitory (Ge et al. 2006). Around the same time, neurons display for the first time large mossy fiber boutons-the structural correlate of the presynaptic compartment of granule neurons-in the hilus and CA3 region, and express electrophysiological evidence and morphological correlates (i.e., dendritic spines) of synaptic glutamatergic input (Esposito et al. 2005; Ge et al. 2006; Zhao et al. 2006; Toni et al. 2007, 2008; Sun et al. 2013). Failure to develop Nmethyl-D-aspartate (NMDA)-receptor-mediated input increases cell death between weeks two and three, indicating that synaptic glutamatergic input during this developmental window is crucial for survival of adult-born neurons (Tashiro et al. 2006).

Glutamatergic input and GABAergic input increases and is refined over an extended period of time. Between 4 and $8 \mathrm{wk}$ after their birth, adult-born neurons display enhanced plasticity (Snyder et al. 2001; Schmidt-Hieber et al. 2004), driven by expression of NR2B-containing NMDA receptors in adult-born neurons (Snyder et al. 2001; Ge et al. 2007), and the protracted development of GABAergic inhibition (Li et al. 2005; Marin-Burgin et al. 2012).

Over the past years, proteins expressed at distinct developmental stages have been identified and have since been used as markers for specific cell types in the hippocampal neurogenic lineage. Notably, most of these proteins are transcription factors, emphasizing the key function of transcriptional control in the regulation of the neurogenic program (Fig. 1).

\section{TRANSCRIPTIONAL REGULATORS} OF STEM-CELL AND PRECURSOR ACTIVITY

A number of studies have consistently reported that maintenance of type 1 cells (to which we will in the following also refer to as neural stem cells for the ease of reading) is crucial to ensure hippocampal neurogenesis throughout life. Key determinants for the function of neural stem cells are its proliferative capacity and its potential to multilineage differentiation ("multipotency").

The arguably best-studied transcription factor in the regulation of neural-stem-cell function is the SRY-related high-mobility group (HMG) box (Sox) family member Sox 2 . Sox 2 is highly expressed in type 1 cells and type $2 \mathrm{a}$ precursor cells (Steiner et al. 2006). Conditional ablation of Sox 2 from the adult hippocampal neurogenic lineage causes a strong reduction of radial type 1 cells and of cell proliferation shortly after induction of recombination ( $\mathrm{Fa}$ varo et al. 2009). The identification of Sox2 targets indicates that Sox 2 controls both proliferative capacity and multipotency of neural stem cells. Sox 2 positively regulates the expression of the nuclear orphan receptor tailless (TLX) (Shimozaki et al. 2011)—an essential transcriptional regulator of proliferation competence in adult neural stem cells (see below) (Shi et al. 2004; Liu et al. 2008, 2010; Zhang et al. 2008; Niu et al. 2011). Sox2 was also found to control the expression of the signaling molecule Sonic hedgehog (Shh) (Favaro et al. 2009). Shh signaling is active in type 1 cells (Ahn and Joyner 2005) and promotes cell proliferation in the adult hippocampal neurogenic niche (Lai et al. 2003). Most intriguingly, Shh partially rescues proliferation and self-renewal defects in Sox2ablated postnatal neural stem cells. Thus, Sox2 and Shh appear to be components of an autocrine signaling loop that regulates neural-stemcell maintenance and proliferation (Favaro et al. 2009). Finally, it was shown that Sox2 inhibits Wnt-signaling-induced transcriptional activation of the proneurogenic transcription factor NeuroD, thereby preventing neuronal differentiation and maintaining stem cells in a multipotent state (Kuwabara et al. 2009).

Analysis of transgenic reporter mice showed that the nuclear orphan receptor TLX is expressed in type 1 cells (Shi et al. 2004; Niu et al. 2011). Full TLX knockout as well as conditional ablation of TLX from type 1 precursors cause loss of proliferation in the adult DG (Shi 
et al. 2004; Zhang et al. 2008; Niu et al. 2011). The loss of proliferation is most likely caused by functional impairment rather than loss of type 1 cells, because cells displaying the typical type 1 cell morphology and marker expression persist in the SGZ of adult TLX-deficient mice (Niu et al. 2011). The importance of TLX for proliferative competence of type 1 cells is further supported by the finding that reintroduction of TLX into the DG of TLX-null mice is sufficient to restore proliferation in type 1 cells (Niu et al. 2011). TLX may control proliferative activity of neural stem cells by suppressing pathways that promote stem-cell quiescence including the cell-cycle inhibitor p21, the p53 pathway, and PTEN-mediated inhibition of phosphoinositide-3-kinase (PI3K) signaling (Zhang et al. 2006; Niu et al. 2011) and by promoting the activity of canonical Wnt signaling (see below) (Qu et al. 2010). TLX recruits the histone deacetylases HDAC3 and HDAC5 (Sun et al. 2007), and the histone demethylase lysine-specific demethylase 1 (LSD1) to repress expression of its targets (Sun et al. 2010). Disruption of TLX/HDAC interaction as well as inhibition of LSD1 activity result in reduced neural-stemcell proliferation, indicating that interaction with these transcriptional corepressors is essential for TLX-dependent regulation of stem-cell proliferation (Sun et al. 2007, 2010).

Repressor element 1-silencing transcription (REST) factor was initially described as a transcription factor that represses neuron-specific gene expression in nonneuronal tissues and undifferentiated neuronal progenitors (Chong et al. 1995; Schoenherr and Anderson 1995). REST is biphasically expressed in the adult hippocampal neurogenic lineage with peak expression in type 1/early type 2 cells and in mature granule neurons (Gao et al. 2011). Conditional ablation of REST from type 1 cells results in a mild increase in the fraction of proliferating type 1 cells at early time points; at a later time point, however, fewer type 1 cells proliferate and the rate of neurogenesis is mildly decreased. REST-deficient neural stem cells display self-renewal defects in vitro and show aberrant histone modifications and derepression of neuronal differentiation genes, such as NeuroD1, suggesting that REST controls neural-stem-cell maintenance by preventing precocious expression of the neuronal differentiation program (Gao et al. 2011).

Consistent with the regulation of type 1 cell activity by extrinsic signals, several proteins have been linked to the regulation of stem-cell maintenance and proliferation, which function as transcriptional effectors in signaling cascades. The activated forms of the transcription factors Smad1 and Smad2 form heteromeric complexes with Smad4 to transcriptionally regulate target gene expression downstream from bone morphogenic protein (BMP)2/4 signaling and transforming growth factor (TGF)- $\beta$ signaling, respectively. Active Smad1 is found in quiescent type 1 cells under physiological conditions (Mira et al. 2010), whereas Smad2 activity is observed in type 1 cells in animal models, which show decreased hippocampal neural-stem-cell activity (Kandasamy et al. 2010). Activation of either pathway reduces proliferation of neural stem cells in vitro (Wachs et al. 2006; Mira et al. 2010), whereas in vivo inhibition of BMP2/4 signaling (Bonaguidi et al. 2008; Mira et al. 2010) and ablation of Smad4 from type 1 cells result in increased mitotic activity in the DG (Mira et al. 2010). Notably, prolonged inhibition of BMP signaling results in stem-cell depletion, suggesting that BMP-regulated transcriptional programs are essential to control stem-cell maintenance and proliferation. Transcriptional targets of the BMP2/4-Smad pathway in the regulation of adult neural stem cells have not been systematically investigated but may include the transcription factors of the inhibitor of DNA binding (Id) and of the Hairy enhancer of split (Hes) families, which control differentiation of precursor cells in neural development (Ross et al. 2003; Kageyama et al. 2005) and were found to be up-regulated in adult hippocampal neural stem cells in response to BMP2/4 signaling (Mira et al. 2010). Most recently, it was suggested that BMP-induced quiescence of cultured neural stem cells is dependent on the expression of the transcription factor NFIX (Martynoga et al. 2013). The same study reported that NFIX overexpression was sufficient to induce 
R. Beckervordersandforth et al.

rapid cell-cycle arrest of neural stem cells without induction of differentiation markers. Most intriguingly, it was shown that enhancers, which were active in quiescent neural stem cells, were enriched in consensus binding sites for NFIX transcription factors, indicating that NFIX may directly regulate the transcription of a quiescence-associated genetic program.

An essential pathway for the generation of dentate granule neurons during embryogenesis and adulthood is canonical Wnt signaling (Galceran et al. 2000; Lee et al. 2000; Lie et al. 2005). Canonical Wnt signaling results in stabilization of $\beta$-catenin, which interacts with the transcription factor of the TCF/LEF family to induce the expression of Wnt target genes (Clevers and Nusse 2012). Canonical Wnt signaling was initially linked, in particular, to niche-induced neuronal fate determination and proliferation of type 3 neuroblasts (see below) (Song et al. 2002; Lie et al. 2005; Kuwabara et al. 2009). Recent data suggest that canonical Wnt signaling may also regulate hippocampal stem-cell activity. Neuronal activity decreases the expression of secreted frizzled-related protein 3 (Sfrp3), a Wnt inhibitor highly expressed by local mature granule neurons. Sfrp3 deletion activates quiescent neural stem cells and promotes newborn neuron maturation, dendritic growth, and spine formation (Jang et al. 2013), suggesting an activity-dependent mechanism governing adult neurogenesis through acute release of tonic inhibitors. Dickkopf1 (Dkk1) is a secreted antagonist of Wnt signaling (Clevers and Nusse 2012). Intriguingly, Dkk1 expression in the DG increases with age; whereas, reducing Dkk1 expression counteracts the age-related decrease in neurogenesis and its associated cognitive decline (Seib et al. 2013), which is in line with the observation that dysfunctional Wnt signaling contributes to age-related decline of hippocampal neurogenesis (Miranda et al. 2012).

Notch signaling has been linked to the control of proliferation, maintenance, and self-renewal in a broad array of stem-cell populations (Koch et al. 2013). In canonical Notch signaling, binding of ligands to the Notch receptor culminates in release of transcriptional repressors from RBPJк-the transcriptional down- stream effector in canonical Notch signalingfollowed by the recruitment of coactivators and the induction of expression of target genes (Baron 2003). Canonical Notch signaling is active in type 1 cells and is absent from neuronally committed precursors (Ehm et al. 2010; Lugert et al. 2010). The importance of Notch signaling for balancing quiescence and proliferation of type 1 cells was shown through genetic manipulation of Notch1 and RBPJк. Forced Notch signaling in type 1 cells via overexpression of the intracellular domain of Notch1 enhanced maintenance and proliferation, whereas conditional ablation of Notch1 resulted in decreased proliferation of type 1 cells in the juvenile (Breunig et al. 2007) and adult hippocampus (Ables et al. 2010), respectively. The strongest phenotype was observed following conditional ablation of RBPJк in type 1 cells. Such manipulation dramatically increased proliferation of type 1 cells and neurogenesis and led to the rapid depletion of the hippocampal neuralstem-cell pool (Ehm et al. 2010; Lugert et al. 2010). It was also found that Notch/RBPJк signaling directly controlled the expression of Sox 2 and that Sox 2 overexpression was sufficient to rescue self-renewal deficits of RBPJKdeficient stem cells in vitro, thus providing evidence that canonical Notch signaling controls maintenance and proliferation in adult hippocampal neurogenesis through the transcriptional regulation of Sox 2 expression (Ehm et al. 2010).

Transcription factors of the Hes family, the Forkhead O-box (FoxO) transcription factor family, the transcriptional repressor Bmi-1, and the transcriptional regulator $\mathrm{Hmga} 2$ can transcriptionally regulate the expression of differentiation inhibitors, cell-cycle inhibitors, and of signaling pathways involved in adult neuralstem-cell control (Molofsky et al. 2003; Kageyama et al. 2008; Nishino et al. 2008; van der Vos and Coffer 2011). Analysis of their respective knockout or transgenic reporter mice implicates these factors in the transcriptional regulation of type 1 cell maintenance and proliferation. Nonetheless, cell-type-specific deletion is pending to unequivocally show their functional significance in type 1 cells. 
Bmi-1 and Hmga2 knockout mice display progressive loss of postnatal stem-cell proliferation and self-renewal, owing to the increased expression of the cell-cycle inhibitors and senescence factors p16(Ink4a) and p19(Arf ), which are transcriptionally repressed by $\mathrm{Bmi}-1$ and Hmga2 (Molofsky et al. 2003; Nishino et al. 2008). Hes5-a bona fide canonical Notch-signaling target-inhibits neuronal differentiation of stem cells in embryonic neurogenesis by transcriptionally antagonizing the function of proneurogenic bHLH transcription factors (Kageyama et al. 2005). Reporter driven by the Hes5 promoter labels both radial and atypical type 1 cells with high specificity, raising the possibility that Notch-dependent Hes5 expression may be involved in the maintenance of hippocampal neural stem cells. The number of hippocampal stem cells in FoxO3 knockout mice is transiently increased at young ages but quickly declined at older ages (Renault et al. 2009). FoxO proteins were initially identified as longevity factors operating downstream from the insulin/insulin-like growth factor (IGF)-1 signaling pathway (Kenyon et al. 1993; Lin et al. 1997). FoxO transcription factors have not only been found to regulate cell-cycle inhibitors, DNA-repair proteins, and detoxifying enzymes (van der Vos and Coffer 2011), but also have been shown to modulate signaling pathways regulating adult neural stem cells. These include the TGF- $\beta$ (Seoane et al. 2004), Wnt (Essers et al. 2005; Paik et al. 2009), and Notch (Kitamura et al. 2007) signaling pathways. A recent ChIP-Seq analysis of adult neural stem/progenitor cells revealed that FoxO3 shares numerous targets with the bHLH transcription factor Mash1/Ascl1 with a conspicuous enrichment at the enhancers of genes involved in proneurogenic pathways (see below) (Webb et al. 2013).

The proneural transcription factor achaetescute homolog 1 (Mash1/Ascl1) is expressed by dividing the type 2 a precursor population (Uda et al. 2007) and promotes their proliferation, specification, and differentiation into neurons (Bertrand et al. 2002; Castro et al. 2011). Mash1/Ascl1 operates downstream from TLX in the control of in vitro stem-cell proliferation (Elmi et al. 2010), and closely interacts with
Notch signaling in neural precursor cells (Yun et al. 2002; Castro et al. 2006). Stem cells react on stimuli by up-regulation of Mash1/Ascl1 and subsequently exit quiescence. Inactivation of Mash1/Ascl1 blocks quiescence exit completely and leaves the cells unresponsive to activating stimuli (Andersen et al. 2014). These results propose a model in which Mash1/Ascl1 integrates inputs from both stimulatory and inhibitory signals and converts them into a transcriptional program activating adult neural stem cells (Andersen et al. 2014). The temporal progression of the transcriptional program seems to be linked to the chromatin landscape at target regions as Mash1/Ascl1 promotes chromatin accessibility during neurogenesis (Raposo et al. 2015).

\section{TRANSCRIPTIONAL REGULATORS OF NEURONAL FATE DETERMINATION}

Conceptually, neuronal fate determination is expected to include down-regulation of transcriptional programs maintaining multipotency and the initiation of neuron-specific gene-expression programs. Based on the initiation of DCX expression in type $2 \mathrm{~b}$ precursors, it is assumed that the cells are fate committed to neurons on transition from the type 2 a stage (Kempermann et al. 2004).

Initiation of DCX expression is preceded by the expression of the SoxB2 transcription factor Sox21 (Matsuda et al. 2012), the T-box-containing transcription factor Tbr2 (Hodge et al. 2008), and the transcriptional coregulator Tis 21 (Attardo et al. 2010). Expression of these transcription factors in the hippocampal neurogenic lineage is highly transient and overlaps only during a very limited time window with the expression of immature neuronal markers.

Sox 21 is expressed in a limited number of type 1 and type $2 \mathrm{~b}$ cells and has its highest expression in type 2 a cells. Retrovirus-mediated overexpression of Sox 21 in highly proliferative precursors stimulates the generation of DCXpositive neurons. Sox 21 knockout mice show defective transition of precursors from the type $2 \mathrm{a}$ to the type $2 \mathrm{~b}$ stage, indicating that Sox 21 is a positive regulator of neuronal lineage 
R. Beckervordersandforth et al.

progression of type 2 a cells in the adult DG (Matsuda et al. 2012).

Tbr2 is a conserved component of the transcription factor cascade controlling the formation of glutamatergic neurons in development and adulthood (Hevner et al. 2006). In the adult dentate granule neuron lineage, Tbr2 expression peaks in type $2 \mathrm{a} / \mathrm{b}$ progenitor cells and is absent from radial glia-like type 1 and type 3 neuroblasts (Hodge et al. 2008). Conditional ablation of Tbr2 from the adult hippocampal neurogenic lineage augments stem-cell proliferation. Similar to the Sox 21 deficiency, loss of Tbr2 inhibits the transition from type 1/2a precursor cells toward DCX-expressing type $2 \mathrm{~b}$ cells, demonstrating that Tbr2 is crucial for progression toward a neuronal fate (Hodge et al. 2012).

The molecular mechanism through which Sox 21 and Tbr 2 control lineage progression of type 2 a cells is not fully understood. Current data suggests that both factors are part of a regulatory network that counteracts the stem-cellpromoting activity of Sox2. ChIP-Seq analysis and transactivation studies suggested that Sox2 and Sox 21 have opposing effects on a number of shared targets in neural stem and precursor cells (Sandberg et al. 2005; Matsuda et al. 2012). Tbr2 was suggested to counteract Sox2-mediated inhibition of differentiation by directly repressing Sox2 expression (Hodge et al. 2012). It is noteworthy that T-box-containing transcription factors recruit $\mathrm{H} 3 \mathrm{~K} 27$-demethylase and H3K4-methyltransferase complexes to establish repressive and permissive epigenetic states at target promoters (Miller et al. 2008), which raises the intriguing possibility that Tbr2 governs neuronal lineage progression through histone modifications at stem-cell promoters and neuronal lineage promoters.

Lineage progression of stem and precursor cells is dependent on cell-cycle length. Increasing cell-cycle length favors symmetric self-renewing divisions of neural stem/precursor cells, whereas shortening of the cell cycle promotes asymmetric divisions resulting in the differentiation of stem/precursor cells (Calegari and Huttner 2003; Calegari et al. 2005; Lange et al. 2009; Salomoni and Calegari 2010; Arai et al.
2011; Artegiani et al. 2011). The transcriptional cofactor Tis 21 is biphasically expressed in the adult hippocampal neurogenic lineage with peak expression in type $2 \mathrm{a} / \mathrm{b}$ precursors and on the maturation of $\mathrm{DCX}^{+} /$calretinin $^{+}$neurons toward mature calbindin-positive neurons (Attardo et al. 2010). Tis21 inhibits $G_{1}$ to $S$ phase transition in diverse cell types through negative regulation of the cyclin D1 promoter (Montagnoli et al. 1996; Guardavaccaro et al. 2000). Tis21 knockout mice and transgenic mice overexpressing Tis 21 under the control of a type1/2-specific promoter display altered cell-cycle characteristics and modulation of lineage progression of precursors (Farioli-Vecchioli et al. 2008, 2009), suggesting that Tis21-dependent transcriptional regulation of cell-cycle control may contribute to neuronal lineage commitment in the adult DG. Analysis of conditional knockout mice with adult neurogenesis-specific deletion of Tis21, however, will be necessary to unequivocally show the function of Tis 21 in cellcycle-regulated neuronal lineage commitment in adult hippocampal neurogenesis.

Simultaneous expression of the basic helixloop-helix transcription factor NeuroD1 and of the homeobox factor Proxl is highly specific for the early dentate granule neuron lineage. Both NeuroD1 and Proxl are transcriptional targets of canonical Wnt signaling (Gao et al. 2009; Kuwabara et al. 2009; Karalay et al. 2011). Expression of NeuroD1 and Prox1 is initiated in type 2 b cells (Steiner et al. 2006, 2008; Hodge et al. 2008). Since the onset of NeuroD1 and Prox1 expression was found to coincide with the appearance of neuronal lineage-specific proteins, these transcription factors were considered prime candidates to control neuronal lineage commitment during adult hippocampal neurogenesis. Indeed, NeuroD1 or Prox1 overexpression promotes neuronal differentiation of neural stem cells in vitro (Hsieh et al. 2004; Gao et al. 2009; Karalay et al. 2011). Conditional ablation of NeuroD1 as well as deletion of Prox1 via conditional ablation or knockdown from the hippocampal neurogenic lineage reduced the generation of DCX-positive immature neurons (Gao et al. 2009; Lavado et al. 2010; Karalay et al. 2011). Whether the reduction in neurogenesis 
was the consequence of impaired neuronal fate determination or of another mechanism remained to be determined. In fact, it was described that Proxl and NeuroD1 expression were essential for survival of late-stage precursors and maturing newborn neurons. Thus, conditional ablation of Proxl increased cell death of immature DCX-expressing neurons and of Tbr2-expressing type 2 precursors ( $\mathrm{La}-$ vado et al. 2010), whereas NeuroD1 deficiency decreased the survival of maturing neurons, which may be the consequence of defects in dendrite development and integration into the hippocampal circuitry (Gao et al. 2009).

Recently, SoxC group transcription factors were discovered as key transcriptional regulators of adult hippocampal neurogenesis (Haslinger et al. 2009; Mu et al. 2012; Feng et al. 2013). The SoxC factors Sox 4 and Sox 11 are almost exclusively expressed in regions of adult neurogenesis. Their expression in the adult hippocampal neurogenic lineage is initiated in type $2 \mathrm{~b}$ precursor cells together with NeuroD1 and Prox1, and parallels the expression of DCX (Haslinger et al. 2009; Mu et al. 2012). Overexpression of either Sox 4 or Sox11 was shown to be sufficient to induce neuron-specific gene expression in adult neural stem cells. Conditional removal of Sox11 significantly reduced the generation of DCX-positive immature neurons and impaired proliferation in the hippocampal neurogenic niche (Wang et al. 2013), whereas combined conditional ablation of Sox 4 and Sox11 from fast dividing precursor cells abolished the expression of DCX in newborn cells ( $\mathrm{Mu}$ et al. 2012).

The expression of SoxC factors in the adult hippocampal neurogenic lineage is highly comparable to their expression pattern in the adult SVZ (Haslinger et al. 2009; Mu et al. 2012) and different embryonic neurogenic lineages (Bergsland et al. 2006; Li et al. 2012; Shim et al. 2012). Similar to the hippocampal neurogenic lineage, deletion of SoxC proteins or of Sox11 alone inhibit lineage progression of neural precursors (Bergsland et al. 2006; Li et al. 2012). Moreover, recent evidence suggests that chromatin remodeling and activation of the Sox 4 and Sox11 loci are key regulatory events in neuronal fate determination of adult neural stem cells (Feng et al. 2013) and maintenance of neuronal identity in adult SVZ neurogenesis (Ninkovic et al. 2013). Consistent with a function of SoxC proteins in neuronal fate determination, ChIP-Seq analysis of neuronally differentiated embryonic stem (ES) cells (Bergsland et al. 2011) and analysis of in vivo developmental and adult neurogenesis (Bergsland et al. 2006; Mu et al. 2012; Wang et al. 2013) showed that SoxC factors control the expression of neuron-specific structural proteins (e.g., $\beta$-tubulin III, DCX, Lis1) that are expressed by immature neurons of many, if not all, subtype lineages during adult and embryonic neurogenesis. Finally, SoxC proteins were shown to be required for neuronal reprogramming of somatic cells and when combined with bHLH transcription factors to enhance the efficiency of reprogramming of somatic cells into specific neuronal subtypes (Mu et al. 2012; Liu et al. 2013). Overall, these data indicate that SoxC proteins transcriptionally regulate neuronal lineage-specific genetic programs during both development and adulthood. Moreover, given the expression and neurogenic function of SoxC factors throughout the generation of multiple neuronal subtypes in development and adulthood, it seems reasonable to assume that SoxC proteins control the expression of neuronal traits shared by developing neurons of all subtype lineages (Bergsland et al. 2006, 2011; Mu et al. 2012). According to the terminal selector hypothesis, neuronal-subtype-specific traits are controlled by a combination of cell-type-specific transcriptional regulators ("terminal selector network") that cooperatively determine the unique geneexpression profiles of individual neuronal cell types (Hobert 2011). If SoxC factors control pan-neuronal traits, which factors constitute the terminal selector network in granule neuron generation and identity? NeuroD1 is part of a common transcription factor sequence specifying glutamatergic neurons in different brain regions (Hevner et al. 2006). Proxl was found to be necessary to maintain the identity of mature DG neurons (see below) (Iwano et al. 2012). Given that the simultaneous expression of NeuroD1 and Proxl defines the early dentate 
R. Beckervordersandforth et al.

granule neuron lineage and that they both operate downstream from canonical Wnt signaling, which is essential for patterning of the hippocampal DG, NeuroD1 and Proxl may be key elements of the terminal selector network specifying the neuron subtype.

\section{TRANSCRIPTIONAL REGULATORS OF MATURATION AND SYNAPTIC INTEGRATION}

Information on the transcriptional regulation of neuronal maturation and functional integration in adult hippocampal neurogenesis is scarce. Presently, only NeuroD1 and cAMP-response element-binding (CREB) protein have been confirmed as essential transcriptional regulators in the control of maturation and synaptic integration of adult-born DG neurons via conditional knockout studies and retrovirusmediated-specific genetic manipulation.

Phosphorylation at Ser133 constitutes the rate-limiting step in the activation of CREB (Gonzalez and Montminy 1989). CREB activity as determined by the presence of phosphorylated CREB ( pCREB) is found in adult-born hippocampal granule cells from 3 to $21 \mathrm{~d}$ after their generation and largely overlaps with the expression of DCX (Nakagawa et al. 2002a,b; Jagasia et al. 2009). pCREB is down-regulated as newborn neurons lose DCX expression and initiate the expression of the mature granule cell marker calbindin (Jagasia et al. 2009). The function of CREB in adult hippocampal neurogenesis has been examined using pharmacological and retrovirus-mediated gene transfer. Systemic delivery of the phosphodiesterase-4 inhibitor rolipram promotes CREB signaling in the adult brain (Nakagawa et al. 2002b; Fujioka et al. 2004). Rolipram treatment was found to promote survival of newborn neurons and to enhance neurite outgrowth and dendritic branching of neurons located in the SGZ. Moreover, broad expression of a dominant-negative CREB inhibitor in the DG abolished the effects of rolipram on neuronal morphology (Fujioka et al. 2004). Similarly, retrovirus-mediated expression of the dominant-negative CREB mutant aCREB specifically in the neurogenic line- age severely impaired dendritic growth (Jagasia et al. 2009) and strongly reduced survival of newly generated cells. Thus, gain- and loss-offunction studies consistently show a key role for CREB signaling in the control of dendritic growth and functional integration of newborn neurons and in the regulation of neuronal survival.

Like CREB activity, expression of NeuroD1 is also required for proper dendritic development and survival in adult hippocampal neurogenesis (Gao et al. 2009). Intriguingly, activity of CREB signaling (Jagasia et al. 2009) and expression of NeuroD1 (Tozuka et al. 2005) in the adult neurogenic lineage are both positively regulated by GABA-induced signaling. Moreover, CREB-signaling-deficient adult-generated cells fail to maintain their neuronal identity and lose expression of neuron-specific genes including NeuroD1 (Jagasia et al. 2009). These observations suggest that CREB and NeuroD1 act in the same signaling pathway to control the development and maturation of adult-born DG neurons, and raise the possibility that CREB may operate upstream of NeuroD1.

Based on the analysis of conventional knockout mice, Tis21 and Krüppel-like factor 9 have been implied in the transcriptional control of morphological development and functional integration in adult hippocampal neurogenesis. However, as conditional removal or functional knockdown of these factors specifically from the adult hippocampal neurogenic lineage has not been reported yet, their direct involvement in the transcriptional regulation of maturation awaits confirmation.

Tis 21 is biphasically expressed in the adult hippocampal neurogenic lineage and shows a second peak of expression on the transition from the immature neuronal stage characterized by the expression of DCX and calretinin toward a mature stage characterized by the down-regulation of DCX and calretinin and the expression of calbindin (Attardo et al. 2010). BrdU pulse chase studies in Tis21 knockout mice revealed, on one hand, a significant reduction of calbindin-positive mature cells and, on the other hand, a significant increase in $\mathrm{DCX}^{+} /$ calretinin $^{+}$immature neurons among 28 -d-old 
newborn cells, suggesting that Tis21 deficiency impaired maturation of adult-generated neurons (Farioli-Vecchioli et al. 2009).

Krüppel-like factor 9 (Klf9) is a member of the evolutionarily conserved zinc finger transcription factor family. Klf9 expression is expressed in calbindin-positive DG neurons. Its expression is initiated around $3 \mathrm{wk}$ after the birth of the new neuron and, thus, roughly coincides with the time when adult neurons begin to receive functional inputs (Scobie et al. 2009). Immature newborn neurons in adult Klf9 knockout mice show decreased formation of tertiary dendrites and the long-term survival of new neurons is severely impaired, leading to the suggestion that Klf9 is essential for the transcriptional regulation of synaptic integration and integration-dependent survival (Tashiro et al. 2006; Scobie et al. 2009).

The receptors for mineralocorticoids and glucocorticoids are differentially expressed in the DG neuron lineage (Garcia et al. 2004). It has been known for a long time that corticoids potently modulate the precursor proliferation and survival of adult-generated cells (Mirescu and Gould 2006). A recent study showed that knockdown of corticosteroid receptors from newborn neurons results in major maturation defects including ectopic positioning, and altered dendritogenesis and synaptogenesis (Fitzsimons et al. 2013). Curiously, the fact that corticoid receptors function as transcription factors on ligand binding has been largely neglected in the context of adult hippocampal neurogenesis and transcriptional downstream targets of these proteins in maturing DG neurons remain unknown.

An unresolved issue is the question of how the identity of mature and functionally integrated DG neuron is maintained. As outlined above, the majority of transcription factors controlling the neuron development is only transiently expressed and is down-regulated in mature cells. The one exception is Prox1, whose expression is maintained in the neurogenic lineage after initiation at the type $2 \mathrm{~b}$ stage. A recent study reported that conditional ablation of Prox1 specifically from newly generated mature neurons results in aberrant expression of CA3 pyramidal cell-specific genes and reduces the expression of calbindin, indicating that Proxl is essential for maintenance of DG neuron identity (Iwano et al. 2012).

\section{CONTROL OF LINEAGE PROGRESSION IN ADULT HIPPOCAMPAL NEUROGENESIS BY TRANSCRIPTIONAL NETWORKS: THE BAMBOO PRINCIPLE, DEEPLY ROOTED YET FLEXIBLE}

The development of a functionally integrated DG neuron follows a stereotypic sequence of molecular and cell biological events, whose order is highly resistant to extrinsic influences. What is the molecular basis controlling the ordered progression through neuronal development?

Transcription factors controlling stem-cell maintenance and proliferation are connected via cross-regulatory loops. Notch signaling through RBPJk, for example, controls Sox 2 expression; TLX expression is regulated by Sox2 (Shimozaki et al. 2011); activity of the PI3K pathway is modulated by TLX (Zhang et al. 2006; Niu et al. 2011), whereas the PI3K-regulated transcription factor FoxO3 controls expression of Notch pathway components (Webb et al. 2013). The involvement of cross-regulatory loops to control specific developmental stages may provide the advantage of a self-regulatory transcriptional network, which on one hand is largely self-sufficient and robust, but on the other hand, can be quickly dissolved by dysregulation of a single factor to induce lineage progression (Fig. 2). Indeed, cross-regulatory transcriptional networks may not be confined to the regulation of stem cells, as it was recently reported that a cross-regulatory network involving Pou3f4, NFIB, and SoxC family transcription factors controls neuronal differentiation in adult subventricular/olfactory bulb neurogenesis (Ninkovic et al. 2013).

The highly overlapping expression pattern of some transcription factors suggests that transcription factors cooperatively activate developmental stage-specific gene-expression programs, whereas the sequential expression pattern of other key transcription factors in adult 
A

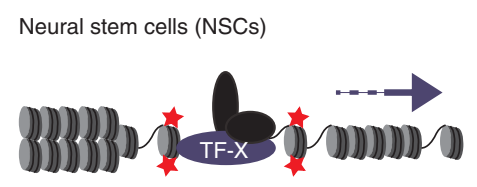

NSC gene transcription

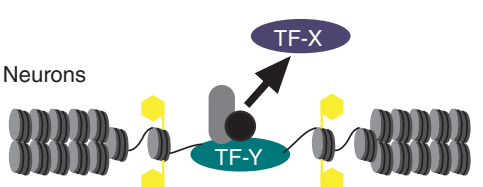

NSC gene repression

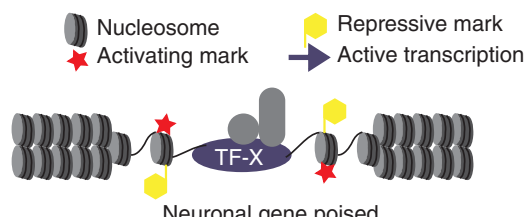

Neuronal gene poised

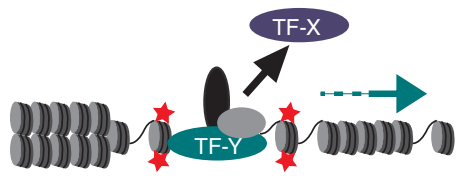

Neuronal gene transcription

B
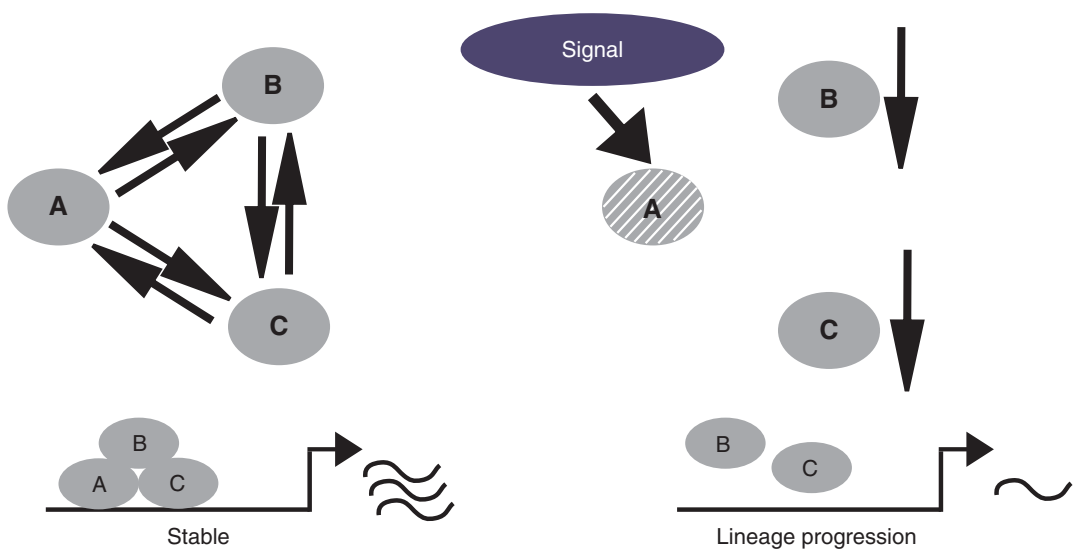

Lineage progression

C
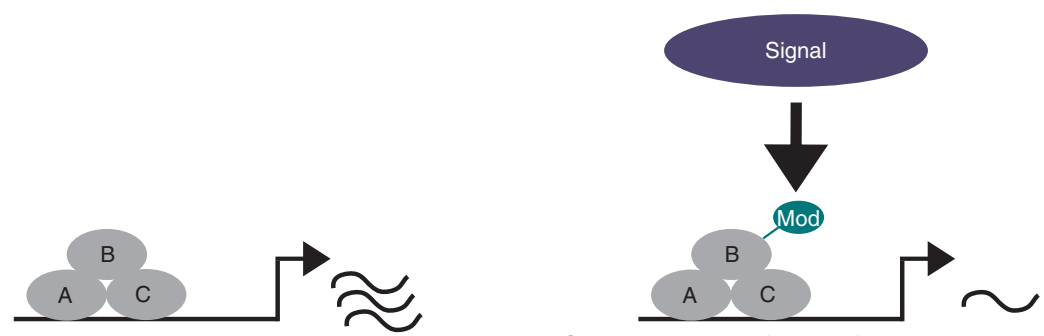

Signal-induced modification of transcription

Figure 2. Emerging mechanisms underlying transcription factor-dependent control of adult hippocampal neurogenesis. (A) Sequential occupancy of enhancers and promoters of key differentiation genes by stagespecific transcription factors during lineage progression. The neural-stem-cell-specific transcription factor $\mathrm{X}$ (TF-X) activates the stage-specific gene-expression program, and additionally primes the cell to express the developmental program of the following step, in this case, a neuron-specific gene-expression program. On lineage progression, the neuron-specific transcriptional regulator transcription factor Y (TF-Y) binds to an overlapping set of enhancers and promoters. TF-Y exerts negative feedback on the gene-expression programs of the preceding developmental step (i.e., the stem-cell program), and activates the neuronal gene-expression program. (B) Cross-regulatory loops provide the advantage of a self-regulatory transcriptional network, which on one hand is largely self-sufficient and robust, but on the other hand can be quickly dissolved by dysregulation of a single factor to induce lineage progression. In this example, transcription factors $\mathrm{A}, \mathrm{B}$, and $\mathrm{C}$ regulate each other and cooperatively regulate stage-specific gene-expression programs. Cross-regulation results in robust levels of all three transcription factors and consequently in stable stage-specific gene expression. Dysregulation of the transcription factor A by a lineage progression signal results in lowered levels of all three transcriptional regulators. As a consequence, the stage-specific gene-expression program cannot be maintained and cells undergo lineage progression. $(C)$ Core regulatory transcription factor networks cooperatively control stagespecific gene-expression programs. The incorporation of transcriptional signal transducers into these networks allows wiring of the activity of extrinsic signals into gene-expression programs. 
neurogenesis raise the possibility that transcriptional regulators exert negative feedback on the gene-expression programs of the preceding developmental step, and prime the developing neuron to express the developmental program of the following step, thereby ensuring lineage progression (Fig. 2). In this regard, it is noteworthy that there is growing evidence for sequential occupancy of enhancers and promoters of key differentiation genes by stage-specific transcription factors during lineage progression. The first example was provided by $\mathrm{Ku}-$ wabara and colleagues, who observed that the NeuroD1 promoter harbored regulatory elements consisting of overlapping Sox2-binding sites and binding sites for the transcriptional effectors of Wnt/ $\beta$-catenin signaling (i.e., Tcell factor/lymphoid enhancer factor [TCF/ LEF] transcription factors). In neural stem cells, Sox2 occupied these Sox/LEF binding sites and repressed the expression of NeuroD1. Induction of neuronal differentiation by canonical Wnt signaling resulted in replacement of Sox 2 by a $\beta$-catenin-containing transcriptional activator complex and expression of NeuroD (Kuwabara et al. 2009). The same study also provided preliminary evidence that binding sites, which can be targeted by both Sox 2 and TCF/LEF transcription factors, may be widely distributed through the genome, raising the possibility that the Sox 2 to TCF/LEF switch may be a general mechanism to express the neuronal differentiation program.

A recent study uncovered that differentiation of ES cells into neurons is accompanied by the sequential expression and binding of the Sox transcription factors Sox2, Sox3, and Sox11 to a common set of neuron-specific gene enhancers. The successive binding of Sox proteins was found to first confer the competence of ES cells to express neural genes and later to drive the proper activation of neuron-specific genes in neuronal precursors and neurons. Binding of an "early" Sox transcription factor to the enhancers of neural- and neuronal-specific genes was associated with chromatin in a poised bivalent state, which, at later developmental stages, was resolved into active chromatin on binding of a "later" Sox factor (Bergsland et al. 2011). Considering the importance of Sox2 for multipotency and proliferation, the crucial function of Sox11 for neuronal differentiation (Mu et al. 2012), and the sequential expression of Sox2, Sox3, and Sox11 in the hippocampal neurogenic lineage (Wang et al. 2006; Haslinger et al. 2009), it is tempting to speculate that a similar binding sequence to neuronal-specific enhancers may contribute to lineage progression in adult hippocampal neurogenesis.

FoxO3 and Mash1 are emerging as another pair of sequentially expressed transcription factors, which share numerous target genes in the adult neurogenic lineage and whose sequential activity may contribute to the regulation of lineage progression. FoxO transcription factors appear to operate on the level of the type 1 stem cells; Mash1 is expressed in the immediate progeny of type 1 stem cells. ChIP-Seq analysis of cultured neural stem cells indicate that FoxO3 and Mash1 target overlapping sets of genes involved in proneurogenic pathways. Intriguingly, analysis of the chromatin landscape suggests that FoxO3 represses and Mash1 activates the expression of neuronal differentiation genes (Webb et al. 2013). These data raise the possibility that FoxO3 regulates stem-cell maintenance by inhibiting the expression of Mash1 target genes and Mash1-induced lineage progression.

Although the order of developmental steps appears to be immutable under physiological conditions, the rate and tempo of adult neurogenesis as well as cell fate choices of precursor cells are subject to modulation by extrinsic signals as revealed by transplantation experiments (Suhonen et al. 1996; Shihabuddin et al. 2000; Lie et al. 2002) and experiments studying the effects of growth-factor-induced signaling (Kuhn et al. 1997; Aberg et al. 2000; Lai et al. 2003; Cao et al. 2004; Lie et al. 2005; Wachs et al. 2006; Bonaguidi et al. 2008; Mira et al. 2010). Most impressively, the adult neurogenic lineage is capable of changing the rate of neuronal production and the developmental time course in response to complex behavioral stimuli (van Praag et al. 2000; Ma et al. 2009; Lugert et al. 2010; Piatti et al. 2011) - a feature that is considered essential to adjust the generation of 
R. Beckervordersandforth et al.

functional integrated neurons for information processing according to changing environmental stimuli.

In several instances, manipulation of different signaling pathways result in comparable phenotypes; for example, loss of Notch signaling (Breunig et al. 2007; Ables et al. 2010; Ehm et al. 2010; Lugert et al. 2010), inhibition of BMP signaling (Mira et al. 2010), and overactivation of PI3K signaling (Bonaguidi et al. 2011) produce transient increases in stem-cell proliferation and in the long-term depletion of type 1 cells and decreased hippocampal neurogenesis; infusion or overexpression of fibroblast growth factor (FGF)-2, Shh, IGF-1, and vascular endothelial growth factor (VEGF) promote stimulation of precursor cell proliferation (Kuhn et al. 1997; Aberg et al. 2000; Lai et al. 2003; Cao et al. 2004). How can such a large number of signals faithfully control the production of new neurons at a rate optimal for hippocampal information processing in the presence of a changing environment and cognitive stimuli? And how can stem cells and their progeny maintain on one hand the stereotypic developmental sequence for the generation of a functional neuron, but on the other hand dynamically respond to extrinsic signals, which can alter the timing of the developmental sequence? To deal with the multitude of regulatory signals, the hippocampal neurogenic niche and cells of the neurogenic lineage themselves are likely to possess mechanisms to integrate extrinsic signals into developmental decisions, such as whether to remain quiescent or to proliferate or whether to speed up or slow down maturation. Transcription factor networks are ideally suited to integrate extrinsic signals into developmental programs (Fig. 2). Developmental neurobiology has for a long time pursued the concept that cellular identity and behavior is controlled by the combinatorial action of cell-type-specific sets of transcription factors (Briscoe and Ericson 2001). Signaling pathways frequently generate transcriptional output by direct control of the activity status of transcription factors through posttranslational modifications. A breakthrough discovery in ES cell research was the identification of a core regulatory transcrip- tional network controlling pluripotency. This core regulatory network is composed of transcription factors, which biochemically interact and cooperatively control the fundamental gene-expression program regulating ES cell identity and function (Boyer et al. 2005, 2006; Chen et al. 2008; van den Berg et al. 2010). Most notably, this core transcriptional network contains transcriptional signal transducers, such as the BMP effector Smad1 and the gp130 signaling effector Stat3, thereby providing a molecular explanation of how the activity of extrinsic signals is wired into the cellular identity network (Chen et al. 2008). Whether equivalent core regulatory transcriptional networks exist, which control distinct steps in hippocampal neurogenesis and modulate the developmental program according to the activity of extrinsic signals, remains to be established. Biochemical and functional interactions of central regulatory transcription factors have been established. Sox 2 and TLX, for example, interact to balance the expression of downstream targets in neural stem cells (Shimozaki et al. 2011). Partnering of Sox2 with the paired related homeobox protein Prxl was found to be highly relevant for neural-stem-cell maintenance as disruption of Prx1 expression has profound effects on in vitro neural-stem-cell self-renewal (Shimozaki et al. 2013).

FoxO transcription factors have the potential to interact with RBPJk (Kitamura et al. 2007) and Smad2/3 (Seoane et al. 2004) and to cooperatively regulate target gene expression. These interactions-if present also in neural stem cells-would be particularly notable as the activity of such complexes could be controlled by multiple signaling inputs, namely, PI3K, Notch, and TGF- $\beta$ signaling, and could allow neural stem cells to integrate different signals and to respond to these signals in a graded fashion (Schwarz et al. 2012).

Neuronal activity is a major stimulus for differentiation and maturation in the adult hippocampal neurogenic lineage (Tozuka et al. 2005; Ma et al. 2009; Piatti et al. 2011; Song et al. 2012, 2013; Zhao et al. 2012). The effects are in part mediated by activity-dependent demethylation and increased expression of sig- 
naling molecules in the hippocampal neurogenic niche (Ma et al. 2009), which may then result in the activation of the respective transcriptional pathways in the hippocampal neurogenic lineage. The observations that increasing GABAergic input onto precursors increases their proliferation and neuronal differentiation and survival (Tozuka et al. 2005; Song et al. 2012, 2013) and that decreasing neuronal excitation of individual newborn neurons delays their maturation (Piatti et al. 2011) show that direct neuronal input into the hippocampal neurogenic lineage exerts major regulatory influence over the developmental sequence. The transcription factor networks downstream from direct neuronal input have not been identified. CREB as a prototypic activity-regulated transcription factor represents a prime candidate to mediate the transcriptional response downstream from neuronal input. Indeed, CREB activity in immature adult-generated neurons is regulated by GABA-induced excitation and controls morphological maturation (Jagasia et al. 2009). CREB itself has the ability to partner with a number of transcriptional regulators, which themselves are regulated by neuronal activity and growth factor signaling; these interactions are thought to enable the CREB transcriptional complex to sense coinciding activities of multiple pathways (Conkright et al. 2003; Ravnskjaer et al. 2007), which, in turn, may allow the developing neuron to interpret a broad variety of signals and convert them into a developmental response (Merz et al. 2011).

\section{CONCLUSION}

Transcription factors as regulators of gene-expression programs exert key functions to control the generation of new functional hippocampal neurons. A growing number of transcriptional regulators for adult hippocampal neurogenesis have now been identified. Yet, as the full complement of key transcriptional regulators in the adult neurogenic lineage has most likely not been discovered, and as there is little insight into the hierarchical order and functional relationship among the individual transcription factors, we are still far from understanding the logic of the transcriptional code coordinating the developmental sequence of adult-born dentate neurons. An additional layer of complexity is presented by the ability of the regulatory network to adapt the rate and timing of the basic developmental sequence in response to complex behavior and molecular signals. If and how these signals are wired into the transcriptional regulation remains largely unknown.

There is growing evidence that the individual transcriptional factor-rather than controlling individual aspects of neuronal development in isolation-participates in a core transcription factor network to control large sets of downstream targets. Moreover, sequential promoter/ enhancer occupancy by developmental stagespecific transcriptional complexes may confer lineage progression by sequential priming, activation, and repression of stage-specific genes. Finally, the activity of extrinsic signals may be directly wired into stage-specific core transcriptional complexes.

Defining the interactome of the transcriptional regulators in adult neurogenesis, and determining the in vivo developmental stagespecific transcriptome and epigenetic landscape will be key to unravel the precise mechanisms underlying transcription factor-mediated regulation. Although such analyses seemed out of reach a few years ago, the recent development of methods to analyze the transcriptome and epigenome from limited in vivo material (Bonn et al. 2012; Grindberg et al. 2013) has opened the door toward an in-depth understanding of the transcriptional basis of adult neurogenesis. Such an understanding will significantly further our insights into the molecular mechanisms underlying neurogenesis-dependent plasticity in health and disease.

\section{ACKNOWLEDGMENTS}

Work in the Lie laboratory is supported by the Bavarian Research Network "ForIPS," the BMBF Network "Cell-Based Regenerative Medicine," the Interdisciplinary Center for Clinical Research of the University Hospital Erlangen, and the Deutsche Forschungsgemeinschaft (LI 858/9-1). Work in the Zhang laboratory is sup- 
R. Beckervordersandforth et al.

ported by the National Institutes of Health (NIH) (1DP2OD006484 and R01NS070981). R.B. is supported by a Grant from the Deutsche Forschungsgemeinschaft (BE 5136/1-1).

\section{REFERENCES}

Aberg MA, Aberg ND, Hedbacker H, Oscarsson J, Eriksson PS. 2000. Peripheral infusion of IGF-I selectively induces neurogenesis in the adult rat hippocampus. J Neurosci 20: 2896-2903.

Ables JL, Decarolis NA, Johnson MA, Rivera PD, Gao Z, Cooper DC, Radtke F, Hsieh J, Eisch AJ. 2010. Notch1 is required for maintenance of the reservoir of adult hippocampal stem cells. J Neurosci 30: 10484-10492.

Ahn S, Joyner AL. 2005. In vivo analysis of quiescent adult neural stem cells responding to Sonic hedgehog. Nature 437: 894-897.

Aimone JB, Deng W, Gage FH. 2011. Resolving new memories: A critical look at the dentate gyrus, adult neurogenesis, and pattern separation. Neuron 70: 589-596.

Andersen J, Urban N, Achimastou A, Ito A, Simic M, Ullom K, Martynoga B, Lebel M, Goritz C, Frisen J, et al. 2014. A transcriptional mechanism integrating inputs from extracellular signals to activate hippocampal stem cells. Neuron 83: 1085-1097.

Arai Y, Pulvers JN, Haffner C, Schilling B, Nusslein I, Calegari F, Huttner WB. 2011. Neural stem and progenitor cells shorten S-phase on commitment to neuron production. Nat Commun 2: 154.

Artegiani B, Lindemann D, Calegari F. 2011. Overexpression of cdk4 and cyclinD1 triggers greater expansion of neural stem cells in the adult mouse brain. J Exp Med 208: 937-948.

Attardo A, Fabel K, Krebs J, Haubensak W, Huttner WB, Kempermann G. 2010. Tis21 expression marks not only populations of neurogenic precursor cells but also new postmitotic neurons in adult hippocampal neurogenesis. Cereb Cortex 20: 304-314.

Baron M. 2003. An overview of the Notch signalling pathway. Semin Cell Dev Biol 14: 113-119.

Beckervordersandforth R, Deshpande A, Schaffner I, Huttner HB, Lepier A, Lie DC, Gotz M. 2014. In vivo targeting of adult neural stem cells in the dentate gyrus by a splitCre approach. Stem Cell Rep 2: 153-162.

Bergsland M, Werme M, Malewicz M, Perlmann T, Muhr J. 2006. The establishment of neuronal properties is controlled by Sox 4 and Sox11. Genes Dev 20: 3475-3486.

Bergsland M, Ramskold D, Zaouter C, Klum S, Sandberg R, Muhr J. 2011. Sequentially acting Sox transcription factors in neural lineage development. Genes Dev 25: 24532464.

Bertrand N, Castro DS, Guillemot F. 2002. Proneural genes and the specification of neural cell types. Nat Rev Neurosci 3: 517-530.

Bonaguidi MA, Peng CY, McGuire T, Falciglia G, Gobeske KT, Czeisler C, Kessler JA. 2008. Noggin expands neural stem cells in the adult hippocampus. J Neurosci 28: $9194-$ 9204.
Bonaguidi MA, Wheeler MA, Shapiro JS, Stadel RP, Sun GJ, Ming GL, Song H. 2011. In vivo clonal analysis reveals self-renewing and multipotent adult neural stem cell characteristics. Cell 145: 1142-1155.

Bonn S, Zinzen RP, Girardot C, Gustafson EH, Perez-Gonzalez A, Delhomme N, Ghavi-Helm Y, Wilczynski B, Riddell A, Furlong EE. 2012. Tissue-specific analysis of chromatin state identifies temporal signatures of enhancer activity during embryonic development. Nat Genet 44: $148-156$.

Boyer LA, Lee TI, Cole MF, Johnstone SE, Levine SS, Zucker JP, Guenther MG, Kumar RM, Murray HL, Jenner RG, et al. 2005. Core transcriptional regulatory circuitry in human embryonic stem cells. Cell 122: 947-956.

Boyer LA, Mathur D, Jaenisch R. 2006. Molecular control of pluripotency. Curr Opin Genet Dev 16: 455-462.

Brandt MD, Jessberger S, Steiner B, Kronenberg G, Reuter K, Bick-Sander A, von der Behrens W, Kempermann G. 2003. Transient calretinin expression defines early postmitotic step of neuronal differentiation in adult hippocampal neurogenesis of mice. Mol Cell Neurosci 24: 603613.

Breunig JJ, Silbereis J, Vaccarino FM, Sestan N, Rakic P. 2007. Notch regulates cell fate and dendrite morphology of newborn neurons in the postnatal dentate gyrus. Proc Natl Acad Sci 104: 20558-20563.

Briscoe J, Ericson J. 2001. Specification of neuronal fates in the ventral neural tube. Curr Opin Neurobiol 11: 43-49.

Calegari F, Huttner WB. 2003. An inhibition of cyclin-dependent kinases that lengthens, but does not arrest, neuroepithelial cell cycle induces premature neurogenesis. J Cell Sci 116: 4947-4955.

Calegari F, Haubensak W, Haffner C, Huttner WB. 2005. Selective lengthening of the cell cycle in the neurogenic subpopulation of neural progenitor cells during mouse brain development. J Neurosci 25: 6533-6538.

Cao L, Jiao X, Zuzga DS, Liu Y, Fong DM, Young D, During MJ. 2004. VEGF links hippocampal activity with neurogenesis, learning and memory. Nat Genet 36: 827-835.

Castro DS, Skowronska-Krawczyk D, Armant O, Donaldson IJ, Parras C, Hunt C, Critchley JA, Nguyen L, Gossler A, Gottgens B, et al. 2006. Proneural bHLH and Brn proteins coregulate a neurogenic program through cooperative binding to a conserved DNA motif. Dev Cell 11: 831-844.

Castro DS, Martynoga B, Parras C, Ramesh V, Pacary E, Johnston C, Drechsel D, Lebel-Potter M, Garcia LG, Hunt C, et al. 2011. A novel function of the proneural factor Ascll in progenitor proliferation identified by genome-wide characterization of its targets. Genes Dev 25: 930-945.

Chen X, Xu H, Yuan P, Fang F, Huss M, Vega VB, Wong E, Orlov YL, Zhang W, Jiang J, et al. 2008. Integration of external signaling pathways with the core transcriptional network in embryonic stem cells. Cell 133: 1106-1117.

Chong JA, Tapia-Ramirez J, Kim S, Toledo-Aral JJ, Zheng Y, Boutros MC, Altshuller YM, Frohman MA, Kraner SD, Mandel G. 1995. REST: A mammalian silencer protein that restricts sodium channel gene expression to neurons. Cell 80: 949-957.

Clevers H, Nusse R. 2012. Wnt/ $\beta$-catenin signaling and disease. Cell 149: 1192-1205. 
Conkright MD, Canettieri G, Screaton R, Guzman E, Miraglia L, Hogenesch JB, Montminy M. 2003. TORCs: Transducers of regulated CREB activity. Mol Cell 12: 413-423.

Ehm O, Goritz C, Covic M, Schaffner I, Schwarz TJ, Karaca E, Kempkes B, Kremmer E, Pfrieger FW, Espinosa L, et al. 2010. RBPJк-dependent signaling is essential for longterm maintenance of neural stem cells in the adult hippocampus. J Neurosci 30: 13794-13807.

Elmi M, Matsumoto Y, Zeng ZJ, Lakshminarasimhan P, Yang W, Uemura A, Nishikawa S, Moshiri A, Tajima N, Agren $\mathrm{H}$, et al. 2010. TLX activates MASH1 for induction of neuronal lineage commitment of adult hippocampal neuroprogenitors. Mol Cell Neurosci 45: 121-131.

Encinas JM, Michurina TV, Peunova N, Park JH, Tordo J, Peterson DA, Fishell G, Koulakov A, Enikolopov G. 2011 Division-coupled astrocytic differentiation and age-related depletion of neural stem cells in the adult hippocampus. Cell Stem Cell 8: 566-579.

Eriksson PS, Perfilieva E, Bjork-Eriksson T, Alborn AM, Nordborg C, Peterson DA, Gage FH. 1998. Neurogenesis in the adult human hippocampus. Nat Med 4: 1313 1317.

Esposito MS, Piatti VC, Laplagne DA, Morgenstern NA, Ferrari CC, Pitossi FJ, Schinder AF. 2005. Neuronal differentiation in the adult hippocampus recapitulates embryonic development. J Neurosci 25: 10074-10086.

Essers MA, de Vries-Smits LM, Barker N, Polderman PE, Burgering BM, Korswagen HC. 2005. Functional interaction between $\beta$-catenin and FOXO in oxidative stress signaling. Science 308: 1181-1184.

Farioli-Vecchioli S, Saraulli D, Costanzi M, Pacioni S, Cina I, Aceti M, Micheli L, Bacci A, Cestari V, Tirone F. 2008. The timing of differentiation of adult hippocampal neurons is crucial for spatial memory. PLoS Biol 6: e246.

Farioli-Vecchioli S, Saraulli D, Costanzi M, Leonardi L, Cina I, Micheli L, Nutini M, Longone P, Oh SP, Cestari V, et al. 2009. Impaired terminal differentiation of hippocampal granule neurons and defective contextual memory in PC3/Tis21 knockout mice. PLoS ONE 4: e8339.

Favaro R, Valotta M, Ferri AL, Latorre E, Mariani J, Giachino C, Lancini C, Tosetti V, Ottolenghi S, Taylor V, et al. 2009. Hippocampal development and neural stem cell maintenance require Sox2-dependent regulation of Shh. Nat Neurosci 12: 1248-1256.

Feng W, Khan MA, Bellvis P, Zhu Z, Bernhardt O, HeroldMende C, Liu HK. 2013. The chromatin remodeler CHD7 regulates adult neurogenesis via activation of SoxC transcription factors. Cell Stem Cell 13: 62-72.

Fitzsimons CP, van Hooijdonk LW, Schouten M, Zalachoras I, Brinks V, Zheng T, Schouten TG, Saaltink DJ, Dijkmans T, Steindler DA, et al. 2013. Knockdown of the glucocorticoid receptor alters functional integration of newborn neurons in the adult hippocampus and impairs fear-motivated behavior. Mol Psychiatry 18: 993-1005.

Fujioka T, Fujioka A, Duman RS. 2004. Activation of cAMP signaling facilitates the morphological maturation of newborn neurons in adult hippocampus. J Neurosci 24: 319-328.

Galceran J, Miyashita-Lin EM, Devaney E, Rubenstein JL, Grosschedl R. 2000. Hippocampus development and generation of dentate gyrus granule cells is regulated by LEF1. Development 127: 469-482.
Gao Z, Ure K, Ables JL, Lagace DC, Nave KA, Goebbels S, Eisch AJ, Hsieh J. 2009. Neurod1 is essential for the survival and maturation of adult-born neurons. Nat Neurosci 12: 1090-1092.

Gao Z, Ure K, Ding P, Nashaat M, Yuan L, Ma J, Hammer RE, Hsieh J. 2011. The master negative regulator REST/ NRSF controls adult neurogenesis by restraining the neurogenic program in quiescent stem cells. J Neurosci 31: 9772-9786.

Garcia A, Steiner B, Kronenberg G, Bick-Sander A, Kempermann G. 2004. Age-dependent expression of glucocorticoid- and mineralocorticoid receptors on neural precursor cell populations in the adult murine hippocampus. Aging Cell 3: 363-371.

Ge S, Goh EL, Sailor KA, Kitabatake Y, Ming GL, Song H. 2006. GABA regulates synaptic integration of newly generated neurons in the adult brain. Nature 439: 589-593.

Ge S, Yang CH, Hsu KS, Ming GL, Song H. 2007. A critical period for enhanced synaptic plasticity in newly generated neurons of the adult brain. Neuron 54: 559-566.

Gonzalez GA, Montminy MR. 1989. Cyclic AMP stimulates somatostatin gene transcription by phosphorylation of CREB at serine 133. Cell 59: 675-680.

Grindberg RV, Yee-Greenbaum JL, McConnell MJ, Novotny M, O'Shaughnessy AL, Lambert GM, Arauzo-Bravo MJ, Lee J, Fishman M, Robbins GE, et al. 2013. RNA-sequencing from single nuclei. Proc Natl Acad Sci 110: 19802-19807.

Guardavaccaro D, Corrente G, Covone F, Micheli L, D’Agnano I, Starace G, Caruso M, Tirone F. 2000. Arrest of $\mathrm{G}_{1}-\mathrm{S}$ progression by the p53-inducible gene $\mathrm{PC} 3$ is $\mathrm{Rb}$ dependent and relies on the inhibition of cyclin D1 transcription. Mol Cell Biol 20: 1797-1815.

Haslinger A, Schwarz TJ, Covic M, Chichung Lie D. 2009. Expression of Sox 11 in adult neurogenic niches suggests a stage-specific role in adult neurogenesis. Eur J Neurosci 29: $2103-2114$.

Hevner RF, Hodge RD, Daza RA, Englund C. 2006. Transcription factors in glutamatergic neurogenesis: Conserved programs in neocortex, cerebellum, and adult hippocampus. Neurosci Res 55: 223-233.

Hobert O. 2011. Regulation of terminal differentiation programs in the nervous system. Annu Rev Cell Dev Biol 27: 681-696.

Hodge RD, Kowalczyk TD, Wolf SA, Encinas JM, Rippey C, Enikolopov G, Kempermann G, Hevner RF. 2008. Intermediate progenitors in adult hippocampal neurogenesis: Tbr2 expression and coordinate regulation of neuronal output. J Neurosci 28: 3707-3717.

Hodge RD, Nelson BR, Kahoud RJ, Yang R, Mussar KE, Reiner SL, Hevner RF. 2012. Tbr2 is essential for hippocampal lineage progression from neural stem cells to intermediate progenitors and neurons. J Neurosci 32: 6275-6287.

Hsieh J, Nakashima K, Kuwabara T, Mejia E, Gage FH. 2004. Histone deacetylase inhibition-mediated neuronal differentiation of multipotent adult neural progenitor cells. Proc Natl Acad Sci 101: 16659-16664.

Iwano T, Masuda A, Kiyonari H, Enomoto H, Matsuzaki F. 2012. Prox1 postmitotically defines dentate gyrus cells by specifying granule cell identity over CA3 pyramidal cell fate in the hippocampus. Development 139: 3051-3062. 
R. Beckervordersandforth et al.

Jagasia R, Steib K, Englberger E, Herold S, Faus-Kessler T, Saxe M, Gage FH, Song H, Lie DC. 2009. GABA-cAMP response element-binding protein signaling regulates maturation and survival of newly generated neurons in the adult hippocampus. J Neurosci 29: 7966-7977.

Jang MH, Kitabatake Y, Kang E, Jun H, Pletnikov MV, Christian KM, Hen R, Lucae S, Binder EB, Song H, et al. 2013. Secreted frizzled-related protein 3 (sFRP3) regulates antidepressant responses in mice and humans. Mol Psychiatry 18: 957-958.

Kageyama R, Ohtsuka T, Hatakeyama J, Ohsawa R. 2005. Roles of bHLH genes in neural stem cell differentiation. Exp Cell Res 306: 343-348.

Kageyama R, Ohtsuka T, Kobayashi T. 2008. Roles of Hes genes in neural development. Dev Growth Differ 50: S97-S103.

Kandasamy M, Couillard-Despres S, Raber KA, Stephan M, Lehner B, Winner B, Kohl Z, Rivera FJ, Nguyen HP, Riess O, et al. 2010. Stem cell quiescence in the hippocampal neurogenic niche is associated with elevated transforming growth factor- $\beta$ signaling in an animal model of Huntington disease. J Neuropathol Exp Neurol 69: 717728.

Karalay O, Doberauer K, Vadodaria KC, Knobloch M, Berti L, Miquelajauregui A, Schwark M, Jagasia R, Taketo MM, Tarabykin V, et al. 2011. Prospero-related homeobox 1 gene (Proxl) is regulated by canonical Wnt signaling and has a stage-specific role in adult hippocampal neurogenesis. Proc Natl Acad Sci 108: 5807-5812.

Kempermann G, Jessberger S, Steiner B, Kronenberg G. 2004. Milestones of neuronal development in the adult hippocampus. Trends Neurosci 27: 447-452.

Kenyon C, Chang J, Gensch E, Rudner A, Tabtiang R. 1993. A C. elegans mutant that lives twice as long as wild type. Nature 366: 461-464.

Kheirbek MA, Klemenhagen KC, Sahay A, Hen R. 2012. Neurogenesis and generalization: A new approach to stratify and treat anxiety disorders. Nat Neurosci 15: $1613-1620$.

Kitamura T, Kitamura YI, Funahashi Y, Shawber CJ, Castrillon DH, Kollipara R, DePinho RA, Kitajewski J, Accili D. 2007. A Foxo/Notch pathway controls myogenic differentiation and fiber type specification. J Clin Invest 117: 2477-2485.

Koch U, Lehal R, Radtke F. 2013. Stem cells living with a Notch. Development 140: 689-704.

Kronenberg G, Reuter K, Steiner B, Brandt MD, Jessberger S, Yamaguchi M, Kempermann G. 2003. Subpopulations of proliferating cells of the adult hippocampus respond differently to physiologic neurogenic stimuli. J Comp Neurol 467: 455-463.

Kuhn HG, Winkler J, Kempermann G, Thal LJ, Gage FH. 1997. Epidermal growth factor and fibroblast growth factor-2 have different effects on neural progenitors in the adult rat brain. J Neurosci 17: 5820-5829.

Kuwabara T, Hsieh J, Muotri A, Yeo G, Warashina M, Lie DC, Moore L, Nakashima K, Asashima M, Gage FH. 2009. Wnt-mediated activation of NeuroD1 and retro-elements during adult neurogenesis. Nat Neurosci 12: 10971105.
Lai K, Kaspar BK, Gage FH, Schaffer DV. 2003. Sonic hedgehog regulates adult neural progenitor proliferation in vitro and in vivo. Nat Neurosci 6: 21-27.

Lange C, Huttner WB, Calegari F. 2009. Cdk4/cyclinD1 overexpression in neural stem cells shortens $G_{1}$, delays neurogenesis, and promotes the generation and expansion of basal progenitors. Cell Stem Cell 5: 320-331.

Lavado A, Lagutin OV, Chow LM, Baker SJ, Oliver G. 2010. Prox 1 is required for granule cell maturation and intermediate progenitor maintenance during brain neurogenesis. PLoS Biol 8: e1000460.

Lee SM, Tole S, Grove E, McMahon AP. 2000. A local Wnt3a signal is required for development of the mammalian hippocampus. Development 127: 457-467.

Li C, Teng RH, Tsai YC, Ke HS, Huang JY, Chen CC, Kao YL, Kuo CC, Bell WR, Shieh B. 2005. H-Ras oncogene counteracts the growth-inhibitory effect of genistein in T24 bladder carcinoma cells. Br J Cancer 92: 80-88.

Li Y, Wang J, Zheng Y, Zhao Y, Guo M, Li Y, Bao Q, Zhang Y, Yang L, Li Q. 2012. Sox11 modulates neocortical development by regulating the proliferation and neuronal differentiation of cortical intermediate precursors. Acta Biochim Biophys Sin 44: 660-668.

Lie DC, Dziewczapolski G, Willhoite AR, Kaspar BK, Shults CW, Gage FH. 2002. The adult substantia nigra contains progenitor cells with neurogenic potential. J Neurosci 22: 6639-6649.

Lie DC, Colamarino SA, Song HJ, Desire L, Mira H, Consiglio A, Lein ES, Jessberger S, Lansford H, Dearie AR, et al. 2005. Wnt signalling regulates adult hippocampal neurogenesis. Nature 437: 1370-1375.

Lin K, Dorman JB, Rodan A, Kenyon C. 1997. daf-16: An HNF-3/forkhead family member that can function to double the life-span of Caenorhabditis elegans. Science 278: $1319-1322$.

Liu HK, Belz T, Bock D, Takacs A, Wu H, Lichter P, Chai M, Schutz G. 2008. The nuclear receptor tailless is required for neurogenesis in the adult subventricular zone. Genes Dev 22: 2473-2478.

Liu HK, Wang Y, Belz T, Bock D, Takacs A, Radlwimmer B, Barbus S, Reifenberger G, Lichter P, Schutz G. 2010. The nuclear receptor tailless induces long-term neural stem cell expansion and brain tumor initiation. Genes Dev 24: 683-695.

Liu ML, Zang T, Zou Y, Chang JC, Gibson JR, Huber KM, Zhang CL. 2013. Small molecules enable neurogenin 2 to efficiently convert human fibroblasts into cholinergic neurons. Nat Commun 4: 2183.

Lugert S, Basak O, Knuckles P, Haussler U, Fabel K, Gotz M, Haas CA, Kempermann G, Taylor V, Giachino C. 2010. Quiescent and active hippocampal neural stem cells with distinct morphologies respond selectively to physiological and pathological stimuli and aging. Cell Stem Cell 6: 445-456.

Lugert S, Vogt M, Tchorz JS, Muller M, Giachino C, Taylor V. 2012. Homeostatic neurogenesis in the adult hippocampus does not involve amplification of Ascl1(high) intermediate progenitors. Nat Commun 3: 670.

Ma DK, Jang MH, Guo JU, Kitabatake Y, Chang ML, PowAnpongkul N, Flavell RA, Lu B, Ming GL, Song H. 2009. Neuronal activity-induced Gadd45b promotes epigenet- 
ic DNA demethylation and adult neurogenesis. Science 323: $1074-1077$.

Marin-Burgin A, Mongiat LA, Pardi MB, Schinder AF. 2012. Unique processing during a period of high excitation/ inhibition balance in adult-born neurons. Science 335: $1238-1242$.

Martynoga B, Mateo JL, Zhou B, Andersen J, Achimastou A, Urban N, van den Berg D, Georgopoulou D, Hadjur S, Wittbrodt J, et al. 2013. Epigenomic enhancer annotation reveals a key role for NFIX in neural stem cell quiescence. Genes Dev 27: 1769-1786.

Matsuda S, Kuwako K, Okano HJ, Tsutsumi S, Aburatani H, Saga Y, Matsuzaki Y, Akaike A, Sugimoto H, Okano H. 2012. Sox 21 promotes hippocampal adult neurogenesis via the transcriptional repression of the Hes5 gene. J Neurosci 32: 12543-12557.

Merz K, Herold S, Lie DC. 2011. CREB in adult neurogenesis-Master and partner in the development of adultborn neurons? Eur J Neurosci 33: 1078-1086.

Miller SA, Huang AC, Miazgowicz MM, Brassil MM, Weinmann AS. 2008. Coordinated but physically separable interaction with $\mathrm{H} 3 \mathrm{~K} 27$-demethylase and H3K4-methyltransferase activities are required for T-box proteinmediated activation of developmental gene expression. Genes Dev 22: 2980-2993.

Ming GL, Song H. 2011. Adult neurogenesis in the mammalian brain: Significant answers and significant questions. Neuron 70: 687-702.

Mira H, Andreu Z, Suh H, Lie DC, Jessberger S, Consiglio A, San Emeterio J, Hortiguela R, Marques-Torrejon MA, Nakashima K, et al. 2010. Signaling through BMPR-IA regulates quiescence and long-term activity of neural stem cells in the adult hippocampus. Cell Stem Cell 7: $78-89$.

Miranda CJ, Braun L, Jiang Y, Hester ME, Zhang L, Riolo M, Wang H, Rao M, Altura RA, Kaspar BK. 2012. Aging brain microenvironment decreases hippocampal neurogenesis through Wnt-mediated survivin signaling. Aging Cell 11: 542-552.

Mirescu C, Gould E. 2006. Stress and adult neurogenesis. Hippocampus 16: 233-238.

Molofsky AV, Pardal R, Iwashita T, Park IK, Clarke MF, Morrison SJ. 2003. Bmi-1 dependence distinguishes neural stem cell self-renewal from progenitor proliferation. $\mathrm{Na}$ ture 425: 962-967.

Montagnoli A, Guardavaccaro D, Starace G, Tirone F. 1996. Overexpression of the nerve growth factor-inducible PC3 immediate early gene is associated with growth inhibition. Cell Growth Differ 7: 1327-1336.

Mu L, Berti L, Masserdotti G, Covic M, Michaelidis TM, Doberauer K, Merz K, Rehfeld F, Haslinger A, Wegner M, et al. 2012. SoxC transcription factors are required for neuronal differentiation in adult hippocampal neurogenesis. J Neurosci 32: 3067-3080.

Nakagawa S, Kim JE, Lee R, Chen J, Fujioka T, Malberg J, Tsuji S, Duman RS. 2002a. Localization of phosphorylated cAMP response element-binding protein in immature neurons of adult hippocampus. J Neurosci 22: 9868 9876.

Nakagawa S, Kim JE, Lee R, Malberg JE, Chen J, Steffen C, Zhang YJ, Nestler EJ, Duman RS. 2002b. Regulation of neurogenesis in adult mouse hippocampus by cAMP and the cAMP response element-binding protein. J Neurosci 22: $3673-3682$.

Ninkovic J, Steiner-Mezzadri A, Jawerka M, Akinci U, Masserdotti G, Petricca S, Fischer J, von Holst A, Beckers J, Lie CD, et al. 2013. The BAF complex interacts with Pax6 in adult neural progenitors to establish a neurogenic crossregulatory transcriptional network. Cell Stem Cell 13: 403-418.

Nishino J, Kim I, Chada K, Morrison SJ. 2008. Hmga2 promotes neural stem cell self-renewal in young but not old mice by reducing p16Ink4a and p19Arf expression. Cell 135: 227-239.

Niu W, Zou Y, Shen C, Zhang CL. 2011. Activation of postnatal neural stem cells requires nuclear receptor TLX. $J$ Neurosci 31: 13816-13828.

Paik JH, Ding Z, Narurkar R, Ramkissoon S, Muller F, Kamoun WS, Chae SS, Zheng H, Ying H, Mahoney J, et al. 2009. FoxOs cooperatively regulate diverse pathways governing neural stem cell homeostasis. Cell Stem Cell 5: 540-553.

Piatti VC, Davies-Sala MG, Esposito MS, Mongiat LA, Trinchero MF, Schinder AF. 2011. The timing for neuronal maturation in the adult hippocampus is modulated by local network activity. J Neurosci 31: 7715-7728.

Qu Q, Sun G, Li W, Yang S, Ye P, Zhao C, Yu RT, Gage FH, Evans RM, Shi Y. 2010. Orphan nuclear receptor TLX activates $W n t / \beta$-catenin signalling to stimulate neural stem cell proliferation and self-renewal. Nat Cell Biol 12: $31-40$

Raposo AA, Vasconcelos FF, Drechsel D, Marie C, Johnston C, Dolle D, Bithell A, Gillotin S, van den Berg DL, Ettwiller L, et al. 2015. Ascl1 coordinately regulates gene expression and the chromatin landscape during neurogenesis. Cell Rep 10: 1544-1556.

Ravnskjaer K, Kester H, Liu Y, Zhang X, Lee D, Yates JR III, Montminy M. 2007. Cooperative interactions between CBP and TORC2 confer selectivity to CREB target gene expression. EMBO J 26: 2880-2889.

Renault VM, Rafalski VA, Morgan AA, Salih DA, Brett JO, Webb AE, Villeda SA, Thekkat PU, Guillerey C, Denko NC, et al. 2009. FoxO3 regulates neural stem cell homeostasis. Cell Stem Cell 5: 527-539.

Ross SE, Greenberg ME, Stiles CD. 2003. Basic helix-loophelix factors in cortical development. Neuron 39: 13-25.

Sahay A, Wilson DA, Hen R. 2011. Pattern separation: A common function for new neurons in hippocampus and olfactory bulb. Neuron 70: $582-588$.

Salomoni P, Calegari F. 2010. Cell cycle control of mammalian neural stem cells: Putting a speed limit on $\mathrm{G}_{1}$. Trends Cell Biol 20: 233-243.

Sandberg M, Kallstrom M, Muhr J. 2005. Sox21 promotes the progression of vertebrate neurogenesis. Nat Neurosci 8: 995-1001.

Schmidt-Hieber C, Jonas P, Bischofberger J. 2004. Enhanced synaptic plasticity in newly generated granule cells of the adult hippocampus. Nature 429: 184-187.

Schoenherr CJ, Anderson DJ. 1995. The neuron-restrictive silencer factor (NRSF): A coordinate repressor of multiple neuron-specific genes. Science 267: 1360-1363. 
R. Beckervordersandforth et al.

Schwarz TJ, Ebert B, Lie DC. 2012. Stem cell maintenance in the adult mammalian hippocampus: A matter of signal integration? Dev Neurobiol 72: 1006-1015.

Scobie KN, Hall BJ, Wilke SA, Klemenhagen KC, Fujii-Kuriyama Y, Ghosh A, Hen R, Sahay A. 2009. Kruppel-like factor 9 is necessary for late-phase neuronal maturation in the developing dentate gyrus and during adult hippocampal neurogenesis. J Neurosci 29: 9875-9887.

Seib DR, Corsini NS, Ellwanger K, Plaas C, Mateos A, Pitzer C, Niehrs C, Celikel T, Martin-Villalba A. 2013. Loss of Dickkopf-1 restores neurogenesis in old age and counteracts cognitive decline. Cell Stem Cell 12: 204-214.

Seoane J, Le HV, Shen L, Anderson SA, Massague J. 2004. Integration of Smad and forkhead pathways in the control of neuroepithelial and glioblastoma cell proliferation. Cell 117: 211-223.

Shi Y, Chichung Lie D, Taupin P, Nakashima K, Ray J, Yu RT, Gage FH, Evans RM. 2004. Expression and function of orphan nuclear receptor TLX in adult neural stem cells. Nature 427: 78-83.

Shihabuddin LS, Horner PJ, Ray J, Gage FH. 2000. Adult spinal cord stem cells generate neurons after transplantation in the adult dentate gyrus. J Neurosci 20: $8727-$ 8735.

Shim S, Kwan KY, Li M, Lefebvre V, Sestan N. 2012. Cisregulatory control of corticospinal system development and evolution. Nature 486: 74-79.

Shimozaki K, Clemenson GD Jr, Gage FH. 2013. Paired related homeobox protein 1 is a regulator of stemness in adult neural stem/progenitor cells. J Neurosci 33: 4066-4075.

Shimozaki K, Zhang CL, Suh H, Denli AM, Evans RM, Gage FH. 2011. Sex determining region Y-box 2 (SOX2) regulation of nuclear receptor tailless (TLX) transcription in adult neural stem cells. J Biol Chem 287: 5969-5978.

Snyder JS, Kee N, Wojtowicz JM. 2001. Effects of adult neurogenesis on synaptic plasticity in the rat dentate gyrus. $J$ Neurophysiol 85: 2423-2431.

Song H, Stevens CF, Gage FH. 2002. Astroglia induce neurogenesis from adult neural stem cells. Nature 417: 39-44.

Song J, Zhong C, Bonaguidi MA, Sun GJ, Hsu D, Gu Y, Meletis K, Huang ZJ, Ge S, Enikolopov G, et al. 2012. Neuronal circuitry mechanism regulating adult quiescent neural stem-cell fate decision. Nature 489: 150-154.

Song J, Sun J, Moss J, Wen Z, Sun GJ, Hsu D, Zhong C, Davoudi H, Christian KM, Toni N, et al. 2013. Parvalbumin interneurons mediate neuronal circuitry-neurogenesis coupling in the adult hippocampus. Nat Neurosci 16: $1728-1730$.

Spalding KL, Bergmann O, Alkass K, Bernard S, Salehpour M, Huttner HB, Bostrom E, Westerlund I, Vial C, Buchholz BA, et al. 2013. Dynamics of hippocampal neurogenesis in adult humans. Cell 153: 1219-1227.

Steiner B, Klempin F, Wang L, Kott M, Kettenmann H, Kempermann G. 2006. Type-2 cells as link between glial and neuronal lineage in adult hippocampal neurogenesis. Glia 54: 805-814.

Steiner B, Zurborg S, Horster H, Fabel K, Kempermann G. 2008. Differential $24 \mathrm{~h}$ responsiveness of Proxl-expressing precursor cells in adult hippocampal neurogenesis to physical activity, environmental enrichment, and kainic acid-induced seizures. Neuroscience 154: 521-529.

Suh H, Deng W, Gage FH. 2009. Signaling in adult neurogenesis. Annu Rev Cell Dev Biol 25: 253-275.

Suhonen JO, Peterson DA, Ray J, Gage FH. 1996. Differentiation of adult hippocampus-derived progenitors into olfactory neurons in vivo. Nature 383: 624-627.

Sun G, Yu RT, Evans RM, Shi Y. 2007. Orphan nuclear receptor TLX recruits histone deacetylases to repress transcription and regulate neural stem cell proliferation. Proc Natl Acad Sci 104: 15282-15287.

Sun G, Alzayady K, Stewart R, Ye P, Yang S, Li W, Shi Y. 2010. Histone demethylase LSD1 regulates neural stem cell proliferation. Mol Cell Biol 30: 1997-2005.

Sun GJ, Sailor KA, Mahmood QA, Chavali N, Christian KM, Song H, Ming GL. 2013. Seamless reconstruction of intact adult-born neurons by serial end-block imaging reveals complex axonal guidance and development in the adult hippocampus. J Neurosci 33: 1140011411.

Tashiro A, Sandler VM, Toni N, Zhao C, Gage FH. 2006. NMDA-receptor-mediated, cell-specific integration of new neurons in adult dentate gyrus. Nature 442: 929933.

Toni N, Teng EM, Bushong EA, Aimone JB, Zhao C, Consiglio A, van Praag H, Martone ME, Ellisman MH, Gage FH. 2007. Synapse formation on neurons born in the adult hippocampus. Nat Neurosci 10: 727-734.

Toni N, Laplagne DA, Zhao C, Lombardi G, Ribak CE, Gage FH, Schinder AF. 2008. Neurons born in the adult dentate gyrus form functional synapses with target cells. Nat Neurosci 11: 901-907.

Tozuka Y, Fukuda S, Namba T, Seki T, Hisatsune T. 2005. GABAergic excitation promotes neuronal differentiation in adult hippocampal progenitor cells. Neuron 47: 803815.

Uda M, Ishido M, Kami K. 2007. Features and a possible role of Mash1-immunoreactive cells in the dentate gyrus of the hippocampus in the adult rat. Brain Res 1171: $9-17$.

van den Berg DL, Snoek T, Mullin NP, Yates A, Bezstarosti K, Demmers J, Chambers I, Poot RA. 2010. An Oct4-centered protein interaction network in embryonic stem cells. Cell Stem Cell 6: 369-381.

van der Vos KE, Coffer PJ. 2011. The extending network of FOXO transcriptional target genes. Antioxid Redox Signal 14: $579-592$.

van Praag H, Kempermann G, Gage FH. 2000. Neural consequences of environmental enrichment. Nat Rev Neurosci 1: 191-198.

Wachs FP, Winner B, Couillard-Despres S, Schiller T, Aigner R, Winkler J, Bogdahn U, Aigner L. 2006. Transforming growth factor- $\beta 1$ is a negative modulator of adult neurogenesis. J Neuropathol Exp Neurol 65: 358-370.

Wang TW, Stromberg GP, Whitney JT, Brower NW, Klymkowsky MW, Parent JM. 2006. Sox3 expression identifies neural progenitors in persistent neonatal and adult mouse forebrain germinative zones. J Comp Neurol 497: 88-100. 
Wang Y, Lin L, Lai H, Parada LF, Lei L. 2013. Transcription factor Sox11 is essential for both embryonic and adult neurogenesis. Dev Dyn 242: 638-653.

Webb AE, Pollina EA, Vierbuchen T, Urban N, Ucar D, Leeman DS, Martynoga B, Sewak M, Rando TA, Guillemot F et al. 2013. FOXO3 shares common targets with ASCL1 genome-wide and inhibits ASCL1-dependent neurogenesis. Cell Rep 4: 477-491.

Winner B, Kohl Z, Gage FH. 2011. Neurodegenerative disease and adult neurogenesis. Eur J Neurosci 33: 11391151.

Yun K, Fischman S, Johnson J, Hrabe de Angelis M, Weinmaster G, Rubenstein JL. 2002. Modulation of the notch signaling by Mash1 and Dlx1/2 regulates sequential specification and differentiation of progenitor cell types in the subcortical telencephalon. Development 129: 5029-5040.
Zhang CL, Zou Y, Yu RT, Gage FH, Evans RM. 2006. Nuclear receptor TLX prevents retinal dystrophy and recruits the corepressor atrophin1. Genes Dev 20: 1308-1320.

Zhang CL, Zou Y, He W, Gage FH, Evans RM. 2008. A role for adult TLX-positive neural stem cells in learning and behaviour. Nature 451: 1004-1007.

Zhao C, Teng EM, Summers RG Jr, Ming GL, Gage FH. 2006. Distinct morphological stages of dentate granule neuron maturation in the adult mouse hippocampus. $J$ Neurosci 26: 3-11.

Zhao C, Deng W, Gage FH. 2008. Mechanisms and functional implications of adult neurogenesis. Cell 132: 645-660.

Zhao C, Warner-Schmidt J, Duman RS, Gage FH. 2012 Electroconvulsive seizure promotes spine maturation in newborn dentate granule cells in adult rat. Dev Neurobiol 72: 937-942. 


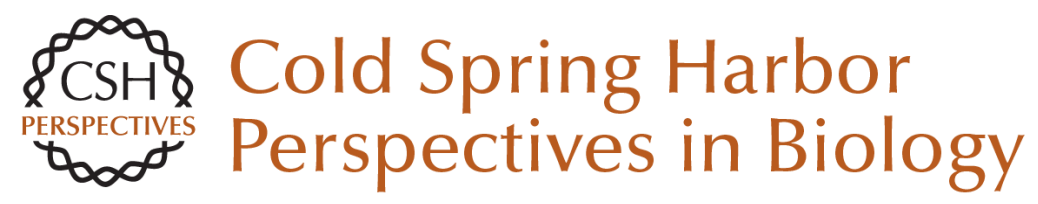

\title{
Transcription-Factor-Dependent Control of Adult Hippocampal Neurogenesis
}

\author{
Ruth Beckervordersandforth, Chun-Li Zhang and Dieter Chichung Lie
}

Cold Spring Harb Perspect Biol 2015; doi: 10.1101/cshperspect.a018879

\section{Subject Collection Neurogenesis}

Adult Neurogenesis and Psychiatric Disorders

Eunchai Kang, Zhexing Wen, Hongjun Song, et al.

Neuronal Circuitry Mechanisms Regulating Adult

Mammalian Neurogenesis Juan Song, Reid H.J. Olsen, Jiaqi Sun, et al.

Neurogenesis in the Developing and Adult Brain

- Similarities and Key Differences

Magdalena Götz, Masato Nakafuku and David Petrik

Genetics and Epigenetics in Adult Neurogenesis Jenny Hsieh and Xinyu Zhao

The Adult Ventricular-Subventricular Zone (V-SVZ) and Olfactory Bulb (OB) Neurogenesis Daniel A. Lim and Arturo Alvarez-Buylla

Diversity of Neural Precursors in the Adult Mammalian Brain

Michael A. Bonaguidi, Ryan P. Stadel, Daniel A. Berg, et al.

Detection and Phenotypic Characterization of Adult Neurogenesis H. Georg Kuhn, Amelia J. Eisch, Kirsty Spalding, et al.

Maturation and Functional Integration of New Granule Cells into the Adult Hippocampus Nicolas Toni and Alejandro F. Schinder
Adult Olfactory Bulb Neurogenesis

Pierre-Marie Lledo and Matt Valley

Adult Neurogenesis in Fish Julia Ganz and Michael Brand

In Vitro Models for Neurogenesis Hassan Azari and Brent A. Reynolds

Engineering of Adult Neurogenesis and Gliogenesis

Benedikt Berninger and Sebastian Jessberger

Computational Modeling of Adult Neurogenesis James B. Aimone

Control of Adult Neurogenesis by Short-Range Morphogenic-Signaling Molecules Youngshik Choe, Samuel J. Pleasure and Helena Mira

Adult Neurogenesis: An Evolutionary Perspective Gerd Kempermann

Epilepsy and Adult Neurogenesis Sebastian Jessberger and Jack M. Parent

For additional articles in this collection, see http://cshperspectives.cshlp.org/cgi/collection/

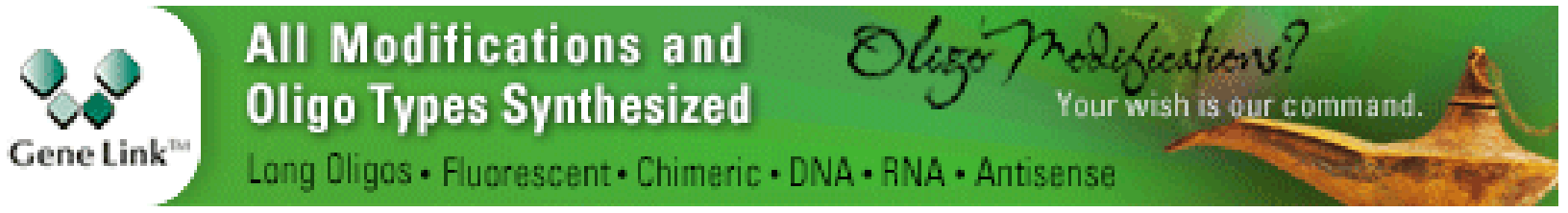


For additional articles in this collection, see http://cshperspectives.cshlp.org/cgi/collection/

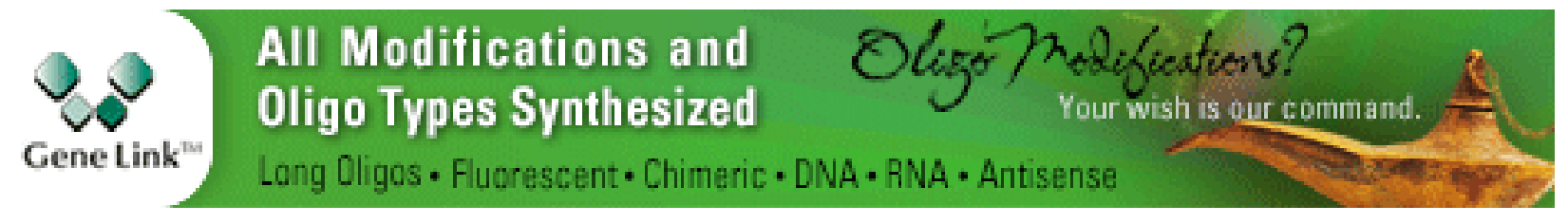

Copyright @ 2015 Cold Spring Harbor Laboratory Press; all rights reserved 